\title{
LA LENGUA DE LA COMEDIA ARISTOFANICA
}

According to the author of this paper there are two kinds of Attic in the basic language used by Aristophanes. One of them is a traditional one and agrees with the data we find in the early Attic inscriptions. The other one is a more regulated kind of Attic in which Ionic influence can be detected. This more standardized Attic is to be considered as the origin of Hellenistic Greek. Further considerations are made concerning the colloquial level of the Aristophanic language.

Tratar de la lengua aristofánica * implica fundamentalmente plantearse tres cuestiones: En primer lugar, el hecho de que se trata de

* Nuestro agradecimiento a la CAICYT por su generoso apoyo al proyecto de investigación n. ${ }^{\circ}$ 0553/81, titulado «Historia de la lengua griega: dialectología y lenguas literarias». He aquí una bibliografía selecta acerca de la lengua de Aristó.

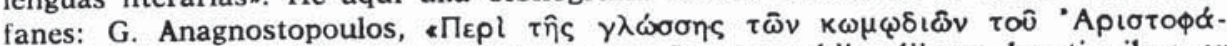
vous". 'A usu vitae petitis apud Aristophanem Comicum, Königsberg 1880; A. Burckhardt, Spuren der athenischen Volksrede in der alten Komödie, Basilea 1924; C. Coulter, "The Speech of Foreigners in Greek and Latin Comedy», ClQ 13, 1934, p. 133 ss.; J. D. Denniston, The Greek Particles, Oxford $1954_{2}$; W. Dittmar, Sprachliche Unter suchungen zu Aristophanes und Menander, Leipzig 1933; K. Dover, «Aristophanes (Comicus) 1938-1955», Lustrum 2, 1957, pp. 52-112; "Greek Comedy», Fifty Years of Classical Scholarship, Oxford 1968, pp. 123-136; «Lo stile d'Aristofane», QUCC 9 , 1970, pp. 7-23; Aristophanes Clouds, Oxford 1970; G. Dunst, Die Wörter des Schimpfens und Spottens in der älteren griechischen Komödie, tes. doct., Berlín 1954; J. Friedrich, "Das Attische im Munde von Ausländern bei Aristophanes», Philologus 25, 1918, pp. 274-301; Th. Gelzer, «Aristophanes der Komiker», RE Suppl. Bd. XII (1970) Nachtr. 1392-1569; E. W. Handley, «-SIS- nouns in Aristophanes», Eranos 21, 1953, pp. 129-142; R. Harriot, «Aristophanes Audience and the Plays of Euripides». BICS 9, 1962, pp. 1-8; R. Hiersche, Grundzüge der griechischen Sprachgeschichte bis zur klassischen Zeit, Wiesbaden 1970, p. 163 ss.; O. Hoffmann-A. Debrunner A. Scherer, Historia de la lengua griega, trad. esp., Madrid 1973, pp. 157-168; E. W. Hope, The Language of Parody: A study in the diction of Aristophanes, tes. doct. Baltimore 1906; C. L. Jungius, De vocabulis antiquae comoediae Atticae quae apud solos comicos aut omnino inveniuntur aut peculiari notione praedita occurrunt. Utrecht-Amsterdam 1897; A. Körte, RE 991 ss.; U. Kronauer, Der formale Witz in den Komödien des Aristophanes, tes. doct., Zürich 1954; O. Lautensach, «Grammatische Studien zu den attischen Tragikern und Komikern», G1. 7, 1916, pp. 92-116; 
una lengua puesta al servicio del efecto cómico. En segundo término, habrá que describir y delimitar muy claramente el ático empleado por Aristófanes en sus comedias, mostrando que representa un hito determinado y concreto de la evolución de este dialecto y que posee un nivel -considerado como dialecto vertical, o desde la perspectiva sociolingüística, si se prefiere- que puede y suele caracterizarse como "ático conversacional». Por último, volviendo a la primera cuestión, habrá que hacer ver de qué manera se produce el contraste entre el ático conversacional empleado por Aristófanes y las distintas variedades lingüísticas de las que hace uso en sus comedias.

En lo cómico existe, en efecto, un contraste entre lo que se percibe y lo que se esperaría percibir. Por eso Sigmund Freud, al estudiar el chiste en su obra Der Witz und seine Beziehungen zum Unbewussten ( $\mathrm{El}$ chiste y su relación con lo inconsciente») ', lo define como «desplazamiento o desviación del proceso mental». Y ya anteriormente Kraepelin hablaba, refiriéndose al chiste, de "caprichosa conexión, conseguida generalmente por asociación verbal, de dos representaciones que contrastan entre sí de un modo cualquiera" ${ }^{2}$. Y en la obra de Lipps y Werner ${ }^{3}$ sobre la comicidad y el humor se hace hincapié en que constituye la esencia de lo cómico "el contraste o contradicción de la significación y la falta de significación de las palabras». H. Bergson, en su

8, 1917, pp. 168-196; K. Lever, "Poetic metaphor and dramatic allegory in Aristophanes», CW 46, 1953, pp. 220-3; O. Lottich, De sermone vulgari Atticorum maxime ex Aristophanis fabulis cognoscendo, Halle 1881; A. Meillet, Aperçu d'une histoire de la langue grecque, París $1975_{8}$, pp. 223-227; H. W. Miller, "Conversational idiom in Aristophanes", CW 38, 1945, pp. 69-113; "Repetition of lines in Aristophanes", AJPh 65, 1944, pp. 26-36; "Comic iteration in Aristophanes", AJPh 66, 1945, pp. 398408; "Aristophanes and the Medical Language», TAPhA 76, 1945, pp. 74-84; "Threeword Iambic Trimeters in Aristophanes", CPh 37, 1942, pp. 194-195; Ch. T. Murphy, "Aristophanes and the art of the rhetoric", HSCP 49, 1938, pp. 69-113; C. W. Peppler, Comic Terminations in Aristophanes and the Comic Fragments, Baltimore 1902: "The Suffix $-\mu \alpha$ in Aristophanes" AJPh 37, 1916, pp. 459-65; "Comic Terminations in Aristophanes", AJPh 42, 1921, pp. 152-61; V. Pisani, Storia della lingua greca, Enciclopedia Classica II, V, Turin 1960, pp. 89-92; J. W. Poultney, The Syntax of the Genitive Case in Aristophanes, Baltimore 1936; L. Radermacher, Aristophanes Frösche, Viena 1954; W. Schmidt-O. Stählin, Geschichte der griechischen Literatur I, IV, reimpr. Munich 1959, p. 425 ss.; E. Schwyzer, Griechische Grammatik I, Munich 1939, p. 111 ss.; E. S. Spyropoulos, L'accumulation verbale chez Aristophane (Recherches sur le style d'Aristophane), Tesalónica 1974; W. J. M. Starkie, The Clouds of Aristophanes, Amsterdam 1960; The Wasps of Aristophanes, Amsterdam 1968; The Acharnians of Aristophanes, Amsterdam 1968; J. Taillardat, Les images d'Aristophane. Etude de langue et de style, París 1965; ; U. v. Wilamowitz-Moellendorff, Aristophanes Lysistrate, Berlín 1927. p. 43.

1 S. Freud, El chiste y su relación con lo inconsciente, trad. esp., Madrid 1969, 2 Ap. S. Freud, o. c., p. 76.

3 Th. Lipps-R. M. Werner, “Komik und Humor», Beiträge zur Aesthetik, 1898. 
famoso estudio sobre la risa y el significado de la comicidad (Le rire, essai sur la signification du comique), ve la raíz de lo cómico en la interferencia de series diferentes de sucesos («l'interférence des séries"): "Une situation est toujours comique quand elle appartient en même temps à deux séries d'événements absolument indépendantes..." 4 . Para Elie Auborim ${ }^{5}$ lo cómico no es sino un juego que consiste en reunir los objetos, las ideas y las impresiones, por más irreconciliables que puedan ser, mediante una presentación, mecanismo o razonamiento ingeniosos. Uno de esos mecanismos - prosigue Auborim - puede ser perfectamente el juego de palabras, en el que una de ellas puede tener dos significaciones diferentes. La presencia de dos elementos unidos bajo una misma apariencia, o bien el doble aspecto de un solo elemento (piénsese en una palabra, una imagen, un gesto o una situación en general), por prestarse a una doble interpretación, provoca el choque o contraste de dos representaciones irreconciliables y con ello nace la comicidad.

Pues bien, el contraste, y concretamente el contraste entendido como lo concibieran los tratadistas anteriormente citados, a saber: el que se produce cuando a determinadas palabras se asocian representaciones que chocan o contrastan entre sí, es la esencia de lo cómico.

Veamos algunos ejemplos que nos facilita la comedia aristofánica:

La homonimia se presta excelentemente al referido contraste de representaciones. No es lo mismo ponerse una coraza para hacer frente a los enemigos en la guerra que emborracharse habiendo empleado como coraza un congio de vino. "Ponerse la coraza" se dice en ático

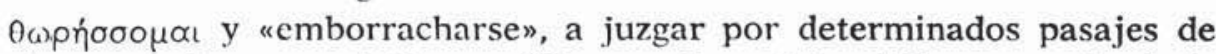
obras que integran el Corpus Hippocraticum ${ }^{6}$, también se puede decir

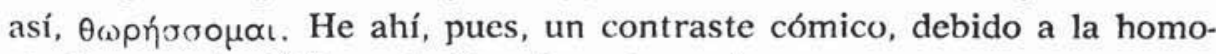
nimia, en este diálogo de Los Acarnienses ?:

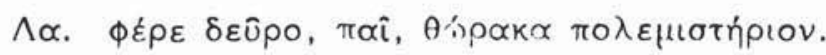

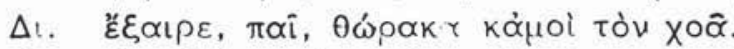

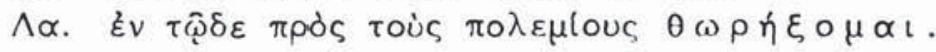

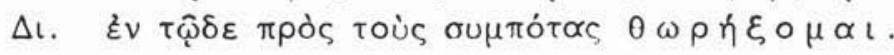

4 H. Bergson, Le rire, essai sur la signification du comique, París 1904, reimpr. París 1972, p. 78.

5 E. Auborim, Technique et psychologie du comique, París 1948.

6 Cf. Hp. Epid. II 5, 10; Morb. 4, 56.

7 Ar. Ach. 1132-1135. [Citamos por la edición oxoniense (OCT): F. W. Hall W. M. Geldart, Aristophanis Comoediae, I, II, reimpr. Oxford 1970.] Cf. R. Frommann, De ambiguorum in Aristophanis comoediis usu, Programm. Danzig 1879; C. Holzinger, De verborum lusu apud Aristophanem (Jahresber. über das Gymnasium der k. k. Theresian. Akademic), Viena 1876. 
El contraste es tremendo, desde luego. Pero además el texto es muy interesante desde el punto de vista lingüístico. Pues no hay que olvidar que la voz $\theta \omega p \eta \dot{\sigma} \sigma o \mu \propto$, con su eta $(\eta)$ en vez de alfa larga ( $\bar{\alpha})$, es un préstamo jónico bien asentado en ático a lo que parece, mientras que la forma $\chi \propto \hat{\alpha}$, con contracción de $\chi \circ \varepsilon \varepsilon \alpha$ en $\chi \circ \hat{\text {, }}$, es voz inequívocamente ática $y$, concretamente, de ese ático que se hablaba en Atenas a finales del siglo v y comienzos del Iv a. J. C., del ático que Aristófanes habló.

Veamos ahora el mismo contraste, pero esta vez motivado, no por

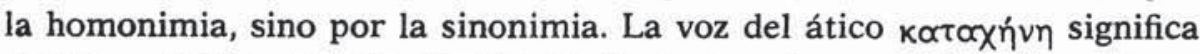
«burla», «mofa», y este significado tiene en este verso puesto en boca de Filocleón en Las Avispas ${ }^{8}$ :

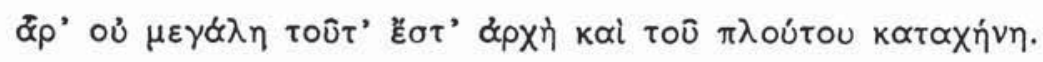

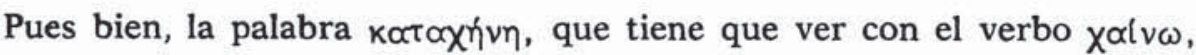
$\chi \alpha ́ \alpha \kappa \omega$, que significa «abrir la boca», tiene un sinónimo o cuasisinónimo en el término $\kappa \propto \tau \not ́ \gamma \varepsilon \lambda \omega \varsigma$, que usa en varias ocasiones Aristófanes ${ }^{9}$.

En Las Asambleístas, refiriéndose al proceso del cambio que va a suponer el comunismo total que las bravas mujeres proponen, dice Praxágora ${ }^{10}$ :

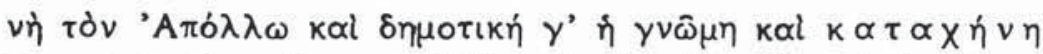

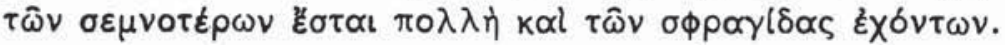

Ya anteriormente una mujer se había referido al proceso calificán-

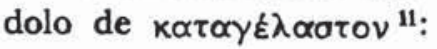

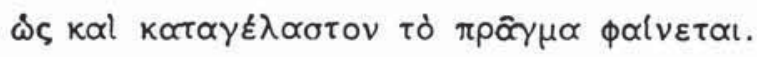

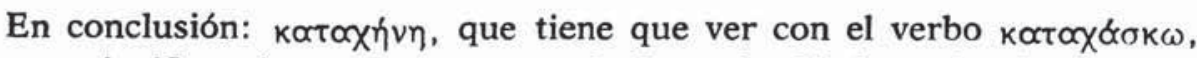
que significa "hacer muecas con la boca burlándose de alguien», es

8 Ar. V. 575

9 Ar. Ach. 1126, 319. Contrastes cómicos basados en la sinonimia son también los siguientes:

Ar. Ach. $380-81$

$\Delta$ เ. $\delta เ \varepsilon \beta \alpha \lambda \lambda \varepsilon \quad k \alpha l \quad \psi \varepsilon \cup \delta \hat{\eta} \quad k \alpha \tau \varepsilon \gamma \lambda \omega \tau \tau ا \zeta \varepsilon \quad \mu o v$

Ar. $R a .1153$

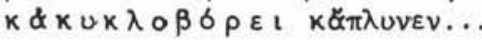

Ar. Ra. $1172-3$

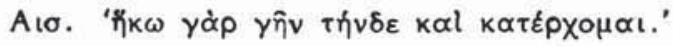

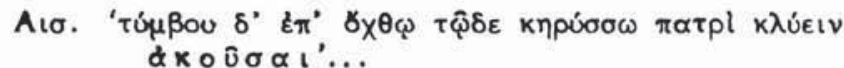

Ar. Ec. 631

11 Ar. Ec. 125 
una voz que por su especial fuerza contrasta con la más usual kotó$\gamma \varepsilon \lambda \omega \varsigma$.

Otro tipo de contraste cómico es el que detectamos en la desproporción entre el contenido o propósito de un mensaje y la forma en que éste se realiza. Por ejemplo: cinco versos de Los Caballeros nos transmiten, medio en serio, medio en broma, con palabras y locuciones del más acendrado y sublime estilo oracular en verso hexamétrico $\mathrm{y}$, al mismo tiempo, con voces disonantes extraídas del ático hablado en la calle y en el mercado todos los días, el oráculo, colmado de reminiscencias literarias ${ }^{12}$, en que se vaticina el triunfo del Salchichero sobre el Paflagonio ${ }^{13}$ :

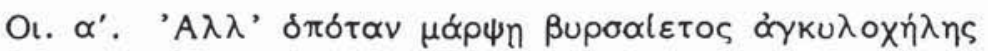

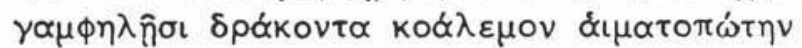

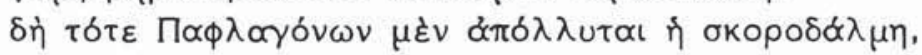

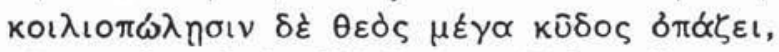

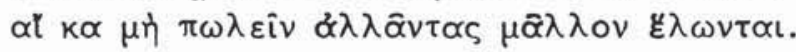

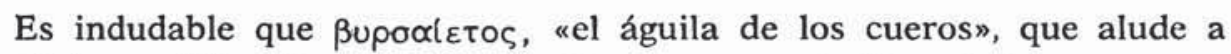

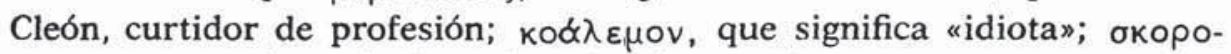
$\delta \dot{\alpha} \lambda \mu \eta$, que quiere decir "salsa de ajo y salmuera"; коเ $\lambda \iota \iota^{\circ} \omega \dot{\omega} \lambda \sigma \iota v$, que equivale en traducción a "vendedores de tripas»; y, por último,

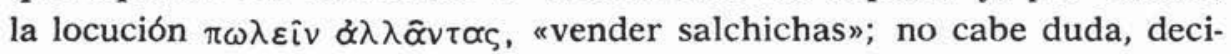
mos, que esta serie de voces y expresiones contrastan fuertemente con el estilo encopetado y críptico de los oráculos revestidos de los atuendos de la épica, que percibimos en los versos hexamétricos del pasaje comentado y en los dativos de plural en - no y en los adjetivos compuestos ( $\alpha^{\prime} \gamma \kappa \cup \lambda \circ-\chi \eta \dot{\eta} \lambda \eta \varsigma$ de nuestro texto nos hace pensar, aun sin que-

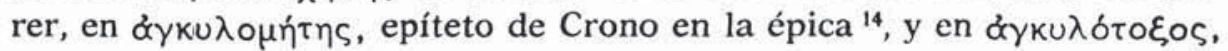
que se dice en la Ilíada de los péones ${ }^{15}$ ), y en la locución Zzù $6 \pi \delta \zeta \varepsilon \varepsilon^{16}{ }^{16}$, que, desde luego, no nos es desconocida. Y en $\propto$ l $\kappa \propto$ hay imitación del estilo oracular délfico.

Habrá, pues, que estudiar más adelante el contraste del ático conversacional con las diferentes lenguas literarias, contraste que es la

12 En el canto XII de la Iliada (It. XII 200-7) se nos ofrece el combate librado por un águila y una serpiente. A la postre, el reptil muerde al rey de las aves, que se deja arrastrar por el viento, mientras que la sierpe va a caer en medio de los troyanos, asustados al contemplar el portento.

13 Ar. Eq. 197-201.

14 Il. II $205, O d$. XXI 415 , etc.

15 Il. II $842, \mathrm{X} 428$.

16 Il. VIII 141. 
esencia y fundamento de la parodia, es decir: de la imitación burlesca de una obra de literatura.

Otras veces el contraste lingüístico es paronímico. Son parónimas aquellas palabras que por su forma o los sonidos de que se componen son muy próximas o semejantes entre sí.

En Las Tesmoforiantes una de las virtuosas damas que celebran la fiesta de las Tesmoforias practicando los mistéricos ritos prohibidos a los hombres llevaba en sus brazos lo que aparentaba ser una niña pequeñita ( $\pi \alpha \iota \delta l o v, \kappa o ́ \rho \eta)$ pero que en realidad era un pellejo de vino. El pariente político de Eurípides le arrebata de pronto la presunta criatura y una mujer compañera de la sufrida madre exclama ${ }^{17}$ :

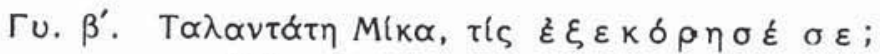

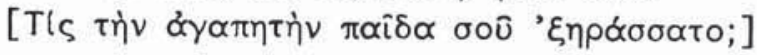

El verbo $\dot{\varepsilon} \kappa \kappa \circ \rho \hat{\varepsilon} \omega$, utilizado por Aristófanes también en $L a P a z{ }^{18}$, aparte del posible valor obsceno derivado del más inocente y primario

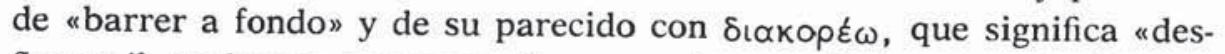
florar» ${ }^{19}$, sugiere la paronomasia кор $\varepsilon$ - "barrer»/ kb́p - "muchacha».

También puede lograrse el contraste cómico modificando una frase hecha o una fórmula, que, mínimamente alterada en una palabra de ella o en unos pocos de sus fonemas, da lugar a una sustancial transformación del significado que se espera. He aquí un ejemplo: Existe una fórmula empleada en las libaciones una vez se ha cumplido el rito,

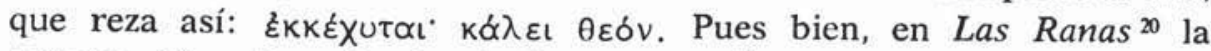
referida fórmula sufre la siguiente mutación:

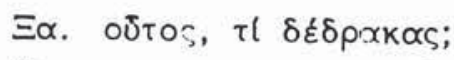

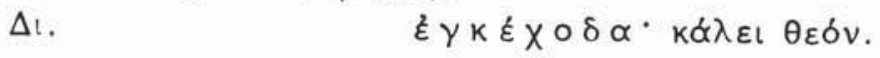

Asimismo pueden producir contraste cómico los diminutivos, que tan pronto aparecen cargados de valor afectivo como desprovistos de él y convertidos en expresión de lo que es más pequeño o reducido de tamaño.

Veamos un pasaje de Las Tesmoforiantes, en el que el pariente político de Eurípides cuenta cómo las mujeres engañan a sus incautos maridos haciéndoles sentirse padres de hijos que no han engendrado. Una vieja - cuenta - enseña a su marido su supuesto hijo y le dice ${ }^{21}$ :

17 Ar. Th. 760 .

18 Ar. Pax 59.

19 Cf. Ar. Th. 480.

20 Ar. Ra. 479.

21 Ar. Th. 514-516. 


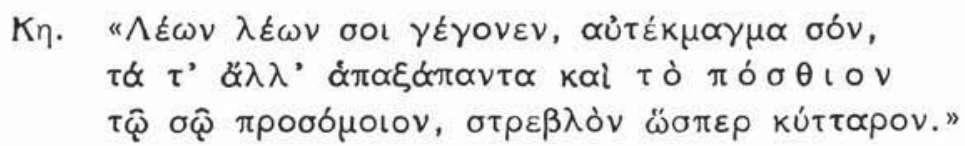

El pobre niñito, que es la viva imagen de su padre, tiene una "colita" que deja de ser tal «colita» cuando se compara a la de su pretendido padre.

Otras veces por analogía respecto de una expresión se arrastra a ella una forma errónea que de este modo se le asimila formalmente, dando así lugar a un contraste entre la forma que se esperaría y la que en realidad aparece. En $\mathrm{La} \mathrm{Paz}$ Trigeo, interpretando la canción de Datis, dice asín:

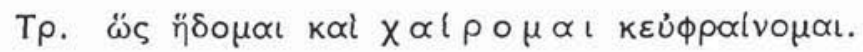

La voz media $\chi \propto l \rho \circ \mu \alpha \iota$ entra en la frase, arrastrada por $\ddot{\eta} \delta \circ \mu \alpha \iota$ y $\varepsilon \dot{u}-$ $\phi \rho \alpha i v o \mu \alpha$. Lo correcto es $\chi \propto \boldsymbol{i} \rho \omega$.

El mismo procedimiento encontramos en estos dos pasajes de Los Caballeros que a continuación reproducimos; dice así el primero ${ }^{23}$ :

Oı. $\beta^{\prime}$. ' $\Omega \varsigma \mu \varepsilon \gamma \alpha \lambda$ ' $\delta \Pi \alpha \phi \lambda \alpha \gamma \dot{\omega} \nu \pi \dot{\varepsilon} \rho \delta \varepsilon \tau \alpha \iota k \alpha l \quad \dot{\rho} \varepsilon \gamma \kappa \varepsilon \tau \alpha$ l.

La forma $\delta \xi \gamma \kappa \varepsilon \tau \propto$, en voz media, es resultado de su aproximación analógica a $\pi \varepsilon \rho \delta \varepsilon \tau \propto \iota$.

He aquí el segundo ejemplo mencionado ${ }^{24}$ :

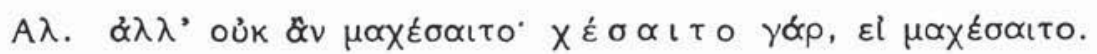

La forma $\chi^{\xi} \delta \alpha \alpha \tau o$, en voz media y no en voz activa (como se esperaría), se explica por el propósito del poeta de hacerla rimar con $\mu \propto x \mathcal{\varepsilon}$ -

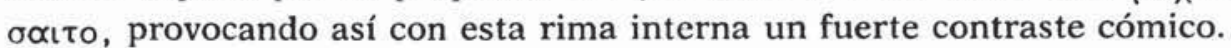
Estas distorsiones, que tienen lugar en la relación del significante y del significado de las palabras o en la de su forma y su función sintáctica, son frecuentísimas en la comedia aristofánica. Veamos un caso, ya no de voz media incorrectamente empleada por analogía con otras formas verbales del mismo verso cuya voz está correctamente usada, sino de rección verbal. Vamos a ver cómo a dos verbos empleados absolutamente, sin complemento, se les traslada un complemento directo que no les corresponde ${ }^{25}$ :

\footnotetext{
22 Ar. Pax 291.

23 Ar. Eq. 115.

24 Ar. Eq. 1057.

25 Ar. Th. 25-28.
} 


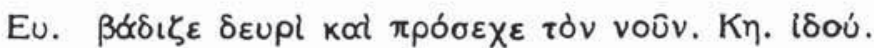

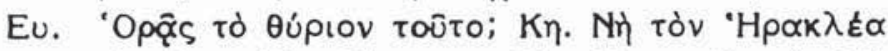

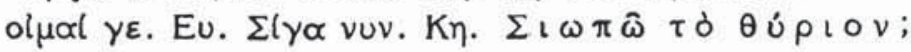

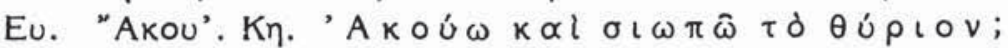

El insensato pariente de Eurípides ha convertido el complemento directo del verbo $\delta \rho \alpha ́ \omega$ ( $\tau \dot{\partial} \theta u ́ p ı o v)$ en complemento directo igualmente

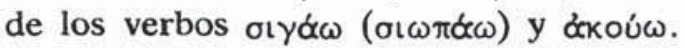

Por último, el contraste cómico lo producen muchas veces, las más de las veces, lo absurdo, lo incongruente y lo inesperado. He aquí algunos ejemplos:

Nada más absurdo que esta cuestioncita que Sócrates planteó a Querofonte ${ }^{20}$ :

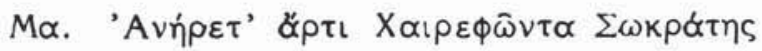

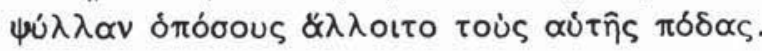

Lingüísticamente el absurdo está en que después del aoristo đ́vípeto, que no es una forma verbal cualquiera ni la que usualmente se emplea en ático para decir "preguntar algo", "plantear una pregunta", pues

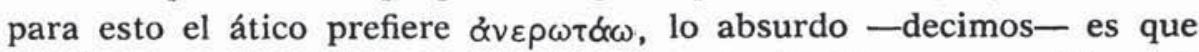
detrás de ese aoristo que emplea en serio Platón en sus diálogos ${ }^{27}$ para decir "plantear cuestiones" aparezca el problema de cómo hallar la relación existente entre la longitud del trecho que salta una pulga y la dimensión de sus patas. Lo incongruente o lo incoherente lo encontramos con frecuencia al servicio de la comicidad en la comedia aristofánica. Por ejemplo: en un par de versos de Las Ranas ${ }^{28}$ Dioniso parodia un poético, serio y filosófico pensamiento que Eurípides plasmara en varias de sus tragedias ${ }^{20}$ y del que también se hará eco el Sócrates de la Apología de Platón. Podría expresarse así: "¿Quién sabe si la vida es muerte?». Pero Aristófanes continúa con hipotéticas ecuaciones: $\alpha \ldots$ $\ldots$ Y si respirar es cenar (obsérvese la asonancia de estas dos palabras en el texto griego original: $\pi \nu \varepsilon \hat{\imath} \nu \ldots \delta \varepsilon เ \pi \nu \varepsilon \hat{\imath} \nu$, asociación fónica, por tanto) y dormir es una manta de pellejito (asociación semántica)?». He aquí el texto en cuestión:

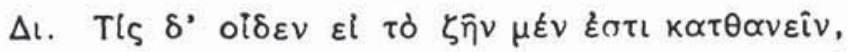

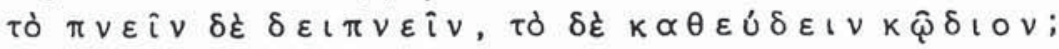

26 Ar. $\mathrm{Nu}$. 144-145.

27 Pl. Smp. 173 b.

28 Ar. $\mathrm{Ra}$. $1477-1478$

29 E. Polid. fr. 639, Erect. fr. 11, Frix. fr. 14 y fr. 830. 
Ocurre con frecuencia que la incongruencia se origina por el parecido formal de dos palabras. Por ejemplo: la semejanza formal entre las voces $\phi \circ i ̂ v เ \xi$, nombre de un ave, y $\phi \hat{k} v \propto \xi$ "embaucador", «impostor», genera el contraste cómico en estos dos versos de Los Acarnienses ${ }^{30}$ :

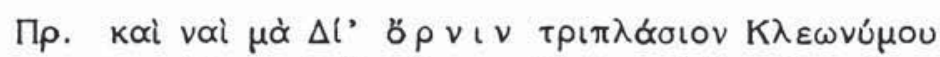

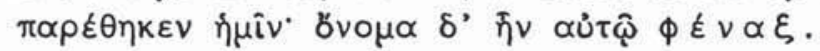

Por último, lo inesperado acecha de continuo detrás de cada palabra y cada frase aristofánicas. Veamos un ejemplo: Existía un refrán o

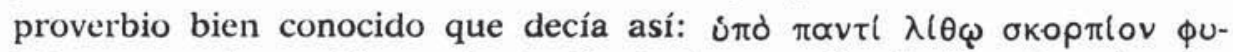
$\lambda \alpha_{\sigma \sigma o \varepsilon \circ}$, en la versión o adaptación hecha por Praxila ${ }^{31}, y$ de este otro modo en uno de los Carmina conuiualia ${ }^{32}$ :

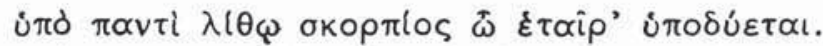

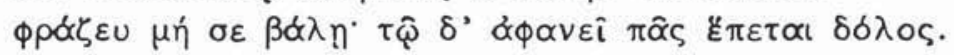

Pues bien, obsérvese cómo en una y otra versión detrás de ítò $\pi \propto v \tau \imath$ $\lambda(\theta \omega$ aparece la voz oкорлtos. Veamos ahora la sorpresa que nos causa Aristófanes cuando, después de referirse al refrán y de citar sus tres primeras palabras, nos sorprende sustituyendo inesperadamente la voz que en buena lógica creemos va a aparecer por otra cuya aparición ni siquiera sospechábamos: $\hat{\phi} \not \uparrow \omega \rho$, la figura del orador, al que, además, como si se tratase de bicho tan dañino como el escorpión, se le atribuye predisposición a pegar mordiscos. He aquí el referido ejemplo ${ }^{33}$ :

$$
\begin{aligned}
& \text { Xo. Tìv } \pi \alpha \rho \circ \mu l \alpha \nu \delta^{\prime} \varepsilon \pi \alpha i v \hat{\omega}
\end{aligned}
$$

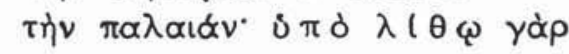

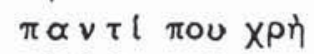

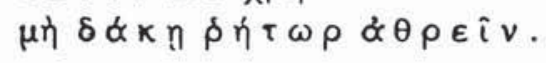

Con frecuencia lo inesperado, la sorpresa, se intensifica mediante recurrencias o reiteraciones: Así, por ejemplo, la pobre Cleonice se siente flaquear y desfallecer después de recitar las dos primeras cláusulas del juramento de abstinencia sexual que le propone Lisístrata (obsérvese cómo estas cláusulas se repiten para hacer más fuerte la sorpresa que producirá el contraste cómico) ${ }^{34}$ :

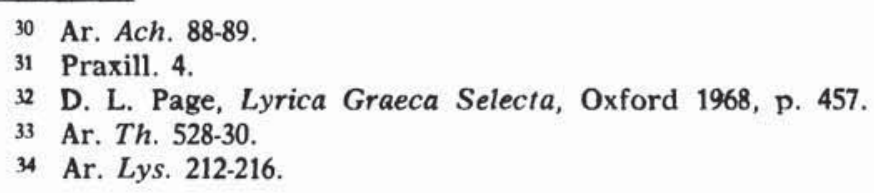




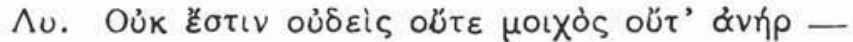

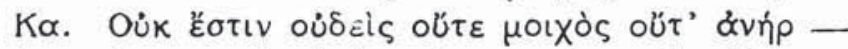

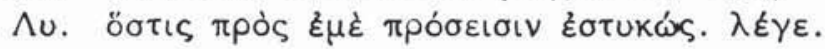

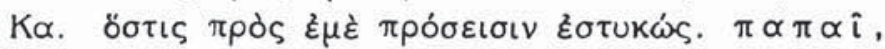

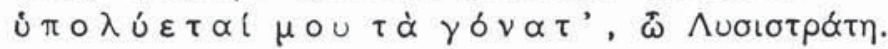

Vamos a ver ahora cómo una serie de repeticiones, de recurrencias de los semantemas "bailar", "cesar", y equivalentes terminan por dar lugar a una inesperada expansión tan cómica como desenfadada ${ }^{35}$ :

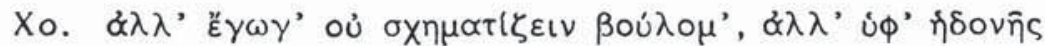

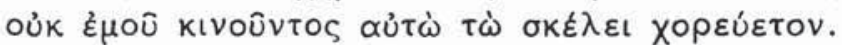

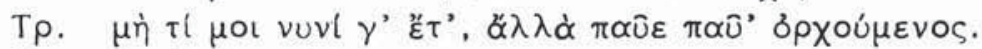

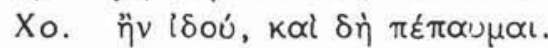

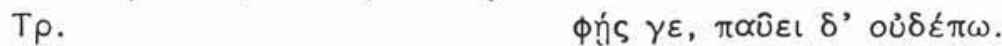

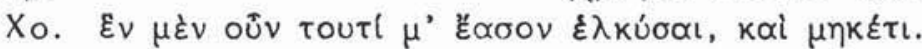

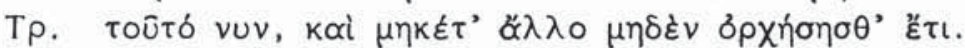

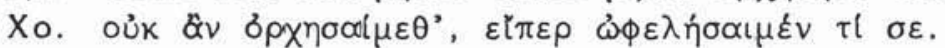

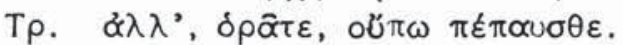

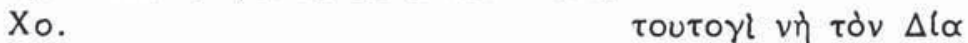

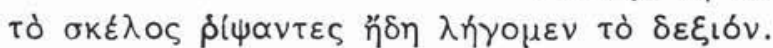

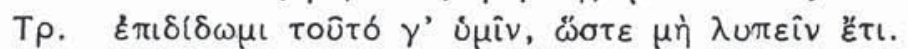

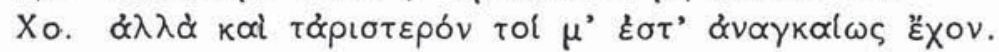

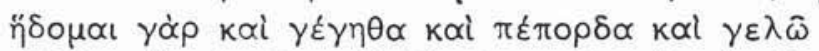

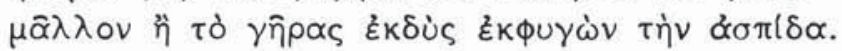

Después del forcejeo entre el Corifeo y Trigeo (aquél sin poder cesar en su danza ni dominar el movimiento de sus piernas que bailan sin control ni tregua al igual que las de los demás miembros del Coro; y éste, harto de tanto baile y tanto regocijo, teniendo como tiene ante sí una hermosísima empresa que acometer), aparecen inesperadamente los fuertes contrastes cómicos en los dos últimos versos: la espontánea y desenvuelta mención de la pedorrera y la alegría y la alusión al cambio de piel de las serpientes («después de haberme despojado de la

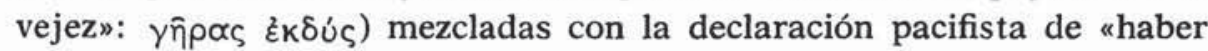
escapado del escudo». El Coro se pee de gozo y alegría por haber logrado inesperadamente la anhelada paz, huyendo así del escudo. Dependiendo del verbo $\varepsilon \kappa \phi \varepsilon u ́ \gamma \omega$ nosotros esperaríamos el nombre de una calamidad, enfermedad o la misma muerte en acusativo, y, en cambio, con el sustantivo $\alpha^{\prime} \sigma \pi i \delta \alpha$ en contextos cómicos y antiheroicos se espera $\alpha \pi \circ \beta \alpha \lambda \varepsilon i \hat{v}$

35 Ar. Pax 324-336. 
para aludir al hecho de arrojar el escudo con el fin de huir más aprisa, como hiciera el traidor Cleónimo ${ }^{36}$. Contraste, reiteración y sorpresa son, por consiguiente, tres factores que se superponen o aparecen imbricados en los versos de la comedia aristofánica. He aquí un ejemplo que ilustra la mencionada imbricación: El pobre Estrepsíades deplora haberse casado con una mujer que ya el mismo día de la boda "olía a perfume, azafrán, besos boca a boca (hasta este momento no hallamos nada excepcional, salvo la recurrencia o acumulación en asíndeton de sustantivos en genitivo) y a dispendio y a glotonería (y aquí empieza ya lo inesperado) y a Afrodita Colíade (nombre este último que sugiere la voz $\kappa \omega \lambda \hat{\eta}$, «miembro viril») y a Afrodita Genitílide (de nuevo esta advocación de la diosa nos hace pensar en el acto de la generación). Y toda esta acumulación verbal ${ }^{37}$ puesta al servicio de la sorpresa y el contraste, a su vez contrasta con el verso precedente en que se nos informa de los olores que - según propia confesión- exhalaba el bueno de Estrepsíades el día de su boda: "olía a mosto, a encella, a vellones de lana, a abundancia». He aquí los tres versos comentados ${ }^{38}$ :

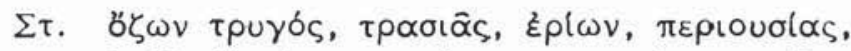

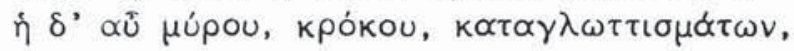

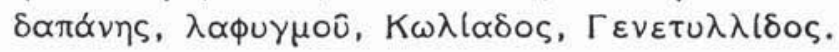

Queda, pues, claro que la lengua de la comedia aristofánica es un tipo de lengua especial que juega al contraste. Ahora bien, ¿cuál es la lengua base que sirve para lograr ese contraste o contraposición subyacente a todo rasgo cómico? La respuesta es inmediata: se trata del ático de nivel coloquial hablado en la Atenas de los últimos años del siglo v y los primeros del siglo IV a. J. C. En la Biblioteca de Focio ${ }^{39}$ se nos transmite doctrina de Frínico el Aticista a propósito de la pureza y carácter castizo del ático empleado en la literatura. He aquí los autores que, en opinión del lexicólogo, son reglas, modelos y ejemplo de ático puro y castizo: Platón, Demóstenes y los otros nueve oradores, Tucídides, Jenofonte, Esquines el filósofo socrático, Critias, Antístenes; entre los trágicos, Esquilo el de la gran voz, el dulce Sófocles y el sumamente sabio Eurípides (los adjetivos no son míos, sino de Frínico o de Focio), y entre los autores de comedias, por supuesto Aristófanes.

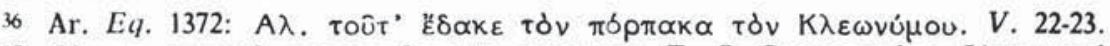

37 Cf., en general, acerca de este concepto, E. S. Spyropoulos, L'accumulation verbale chez Aristophane, Tesalónica 1974.

38 Ar. $\mathrm{Nu}$. 51-53.

39 Phot. Bibl. p. 101 b, 11 ss. (R. Henry, Photius, Bibliotheque, II, París 1960, p. 118). 
A nosotros no nos gusta demasiado la expresión «ático puro», porque sobre la pureza de las lenguas habría mucho que hablar. Olvidemos, pues, esa definición, que, sin embargo, suele aún arrastrarse por los manuales al uso ${ }^{40}$.

La lengua de la comedia aristofánica, por un lado, muestra una serie de rasgos que caracterizan al ático frente a los demás dialectos del grupo jónico-ático, que casi todos, andando el tiempo, perdurarán en griego helenístico, en koiné; por ejemplo: el hecho de que aparezca $\bar{\alpha}$ en vez de $\eta \operatorname{tras} \iota, \varepsilon, \rho^{41}$; la geminada $-\tau \tau$ - o inicial $\tau$ - frente a $-\sigma \sigma-o$ inicial $\sigma$ - del resto del jónico-ático ${ }^{42}$; la geminada $-\rho p$ - procedente de ${ }^{*}$-po- ${ }^{43}$; la inexistencia de alargamiento en la vocal que precedía a grupos de sonante seguida de $F$, por ejemplo: la $\varepsilon$ de $\xi_{\text {ćvvos }}$ frente al jonio minorasiático y de las Cícladas $\xi \varepsilon i v \operatorname{vos}^{44}$; la conservación de la aspiración inicial frente a la psilosis del jonio de Asia Menor ${ }^{45}$; la mayor frecuencia de la contracción de vocales frente al jónico ${ }^{46}$; el genitivo de plural de la primera declinación en $-\hat{\omega} v$ y no en $-\varepsilon \omega \nu \nu^{47}$; el genitivo de singular de los masculinos en $\bar{\alpha}$ acabado en -ov y no en $-\varepsilon \omega^{48}$;

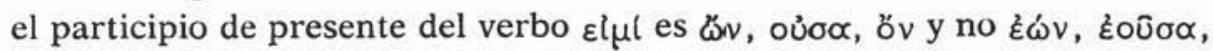
$\varepsilon \delta v^{49}$; la primera persona de plural del presente de indicativo de este mismo verbo es $\varepsilon \sigma \mu \varepsilon v^{50}$ y no $\varepsilon l \mu \varepsilon v \nu$, como en jonio; Aristófanes escribe

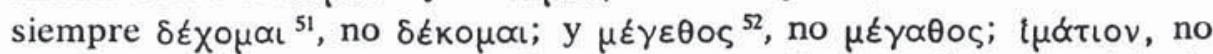

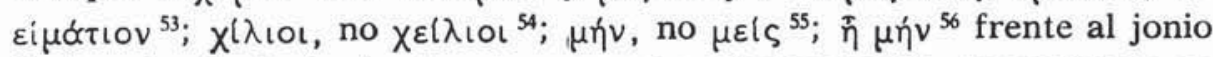
$\bar{\eta} \mu \varepsilon v$, etc. Es decir: hasta este momento, efectivamente, constatamos en la lengua de Aristófanes rasgos típicamente áticos, caracterizadores de

40 R. Hiersche, Grundzüge der griechischen Sprachgeschichte bis zur klassischen Zeit, Wiesbaden 1970, p. 163: “... das Muster des reinsten Attisch. Das gilt durchaus für den Grundstockn. U. v. Wilamowitz-Moellendorff, Aristophanes Lysistrate, p. 31: «Die Sprache gilt den Grammatikern der Kaiserzeit für das reinste Attisch»; p. 33: "Ionismen gibt es in der ältesten Tragödie, die Komödie kennt sie nicht».

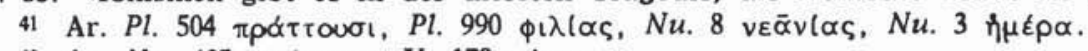

42 Ar. Nu. $605 \pi \rho \alpha \tau \tau \omega \nu, V .179 \tau \hat{\eta} \mu \varepsilon \rho \circ$.

43 Ar. Nu. 663 ๕̊ppeva.

44 Ar. V. 1221 ÉEvos.

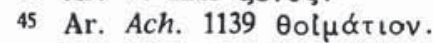

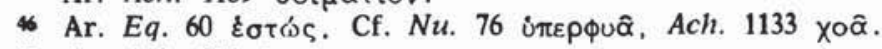

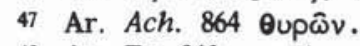

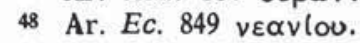

4 Ar. Ach. 46 Бv.

50 Ar. Ach. $504 \varepsilon \sigma \mu \varepsilon v$.

51 Ar. Au. $1276 \delta \varepsilon_{\chi \circ} \circ \alpha \mathrm{L}$.

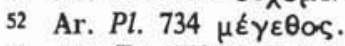

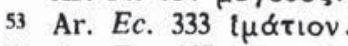

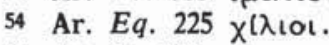

55 Ar. fr. $278 \mu$ रेv.

56 Ar. V. 643 † $\mu \dot{\eta} v$. 
este dialecto. Pero, bien examinada, la lengua aristofánica ofrece un amplio conjunto de formas dobles de una misma categoría gramatical, de las cuales las unas (las que vamos a citar en primer lugar al examinar cada pareja) son más propiamente áticas, más castizas, o están más en consonancia con la lengua de las inscripciones o constituyen, en suma, el arcaísmo; las otras, empero, que citaremos en segundo orden, son resultado de la modernización del dialecto ático que se nivela con el jónico o bien se autosimplifica y regulariza a base de eliminar peculiaridades y rasgos irregulares para constituir así una variedad de ático que va a ser el embrión del griego helenístico. Ya a partir del apartado 47 estudiaremos los puntos de contacto de la lengua aristofánica con la koiné.

Pasamos a examinar, pues, primeramente esos pares de formas contrapuestas: 1) $s p h$ frente a $s p$ : oфupós (Pax 790), por un lado, y

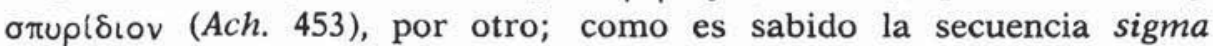
más oclusiva aspirada es más propiamente ática (y propia, además, del jónico occidental) que la equivalente formada por sigma y oclusiva sor$\mathrm{da}$, característica más bien del jónico $\mathrm{y}$, posteriormente, del griego helenístico. 2) También nos encontramos con las parejas gúv ( $\mathrm{Nu} .580)$, acorde con la lengua de las inscripciones áticas, y oúv (Pl. 144), que será la única forma de esta preposición y preverbio en griego posterior, y żৎ (Ach. 32) y $\varepsilon l \varsigma$ (Ach. 28), de las cuales sólo sobrevivirá la última. 3) El diptongo final $-\eta \iota$, procedente de ${ }^{*}-\varepsilon \propto \iota$ en segundas personas de singular de verbos en voz media, o bien aparece así, tal cual, por ejemplo $\sigma \kappa \dot{\omega} \psi n[\varsigma](N u$. 296) o bien con su primer elemento abreviado, por

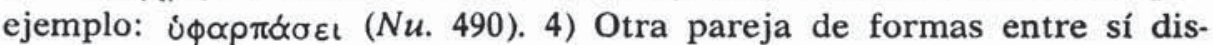

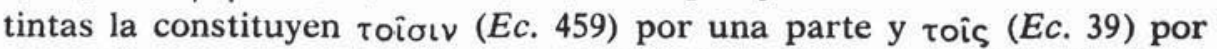

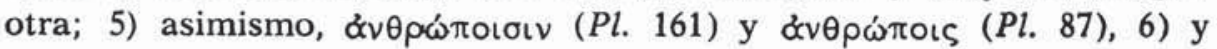

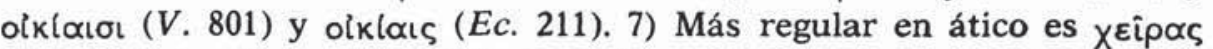

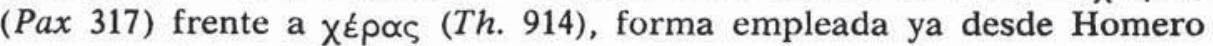
por comodidad métrica. 8) El acusativo de plural b̌pvīs (Au. 717) cons-

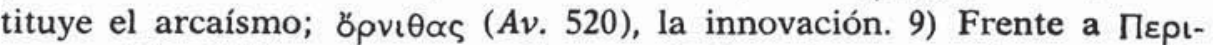
$\kappa \lambda \varepsilon ́ \eta \varsigma(N u$. 895) encontramos formas de la misma especie, pero más

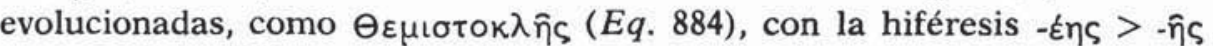

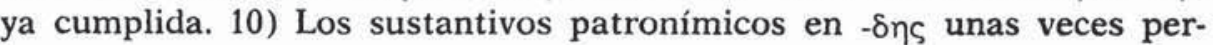
manecen fieles a la primera declinación, a la que pertenecen: Teı $l_{\alpha \delta} \delta$ ( $V .407)$; otras, en cambio, pasan a la tercera declinación, en la que se confunden con los temas en *-s: $\Sigma \tau p \varepsilon \psi(\alpha \delta \eta \bar{~}(N u$. 1206). 11) En cuanto al comparativo, nos topamos en Aristófanes con formas como $\beta \varepsilon \lambda \tau$ lous (Ach. 650), pero asimismo con otras del tipo de $\beta \varepsilon \lambda \tau$ loves (Ec. 240). 12) La primitiva desinencia de segunda persona de voz medio-pasiva *-so

LIV, $2.0-5$ 
perdió su sigma intervocálica, pero posteriormente se asiste en ático, como es sabido, a una paulatina restitución analógica de -s- que culmina en la koiné, donde la extensión de la desinencia - $\sigma o$ se generalizó. Pues

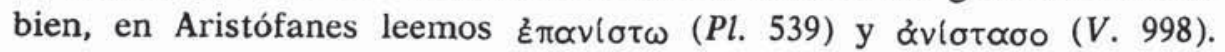
13) En las personas de plural de los aoristos radicales atemáticos con kappa en voz activa, tan pronto nos encontramos con formas $\sin k$, lo que en principio es de esperar: ह̌ $\delta \circ \sigma \propto \nu ~(V .717)$, como con formas provistas de ella por analogía con las tres primeras personas del singular de la voz activa: $\pi \propto \rho \varepsilon \delta \omega \kappa \alpha \nu$ (Nu. 968). 14) Hay junto a segundas personas de singular de imperativos de verbos atemáticos constituidas por el tema puro, como $\varepsilon \xi \varepsilon \iota ~(N u$. 633), otras formadas, por analogía con los temáticos, añadiendo a su radical una $-\varepsilon$, vocal temática: $\delta 1 \delta 00$ (Ach. 1054). 15) Y esta doble formación de la segunda persona de singular de imperativos se registra también en el tema de aoristo; así, junto a formaciones atemáticas del tipo de $\pi i \theta_{\iota}(V .1489)$ hallamos otras

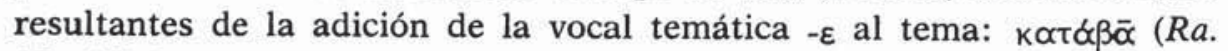
35). 16) Respecto de la primera persona de singular del imperfecto del verbo $\varepsilon l \mu l$, contamos en la lengua aristofánica con dos formas distintas, una más antigua: $\hat{\eta}(E q .1339)$ y otra más moderna: $\mathfrak{\eta} v(N u .530)$. 17) Frente al futuro $(\pi \varepsilon \rho \iota) \delta \rho \propto \mu \varepsilon i \tau \propto \iota ~(V .138)$, de reconocida prosapia, cuenta la lengua de Aristófanes con el futuro más moderno y regularizado $(\pi \varepsilon \rho \iota) \chi \theta \varepsilon \varepsilon \varepsilon \varepsilon \iota$ (Ra. 193). 18) Algo similar cabe decir respecto de la oposición entre los futuros $\beta \alpha \lambda \varepsilon$ îs (Ach. 283) y $\beta \alpha \lambda \lambda \eta \dot{\sigma o o} \mu \varepsilon v(V .222)$;

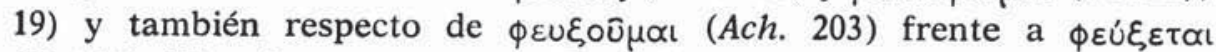
$(V .157), 20)$ y de $\kappa \lambda \propto \cup \sigma o u ́ \mu \varepsilon \theta \propto$ (Pax 1081) en comparación con $\kappa \lambda \propto u ́ \sigma \varepsilon-$ $\tau \propto \iota .21)$ Hay asimismo gran diferencia entre la forma de un futuro

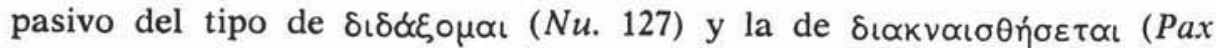
251). El primero es un futuro de voz media empleado con valor pasivo.

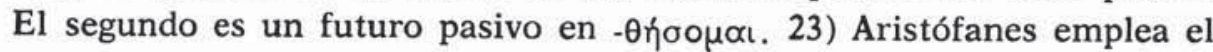

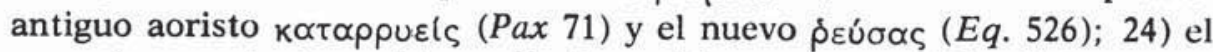
normal y corriente aoristo radical temático $\delta\llcorner\propto \lambda \iota \pi \omega \nu(N u$. 496) y el ya

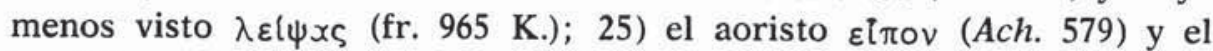

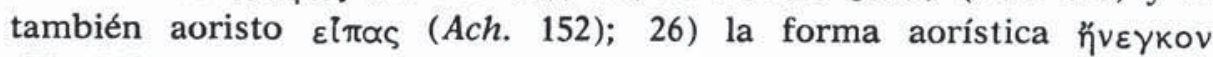

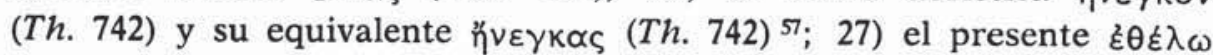
( $E q .791$ ), que es el empleado en las inscripciones del Atica hasta el siglo III a. J. C., y la forma, también de presente, $\theta \dot{\varepsilon} \lambda \omega$ (Eq. 713); 28) el imperfecto $\varepsilon_{\mu} \mu \lambda \lambda{ }_{\lambda} \circ \nu$ ( $E q$. 267), que es la forma propiamente ática, y $\eta \mu \varepsilon \lambda \lambda$ ov (Ec. 597), también imperfecto, forma desconocida en las antiguas inscripciones áticas; 29) el aoristo $\kappa \propto \theta \hat{\imath} \sigma \varepsilon \nu(R a .911)$ con

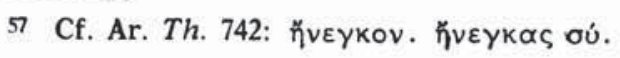


su aumento temporal, y el imperfecto $\varepsilon_{\kappa} \alpha \theta i \zeta \circ 0(V .824)$, provisto del aumento $\varepsilon$ - colocado delante del preverbio $\kappa \alpha \theta-; 30$ ) el adverbio $\tau \alpha \chi u ́$

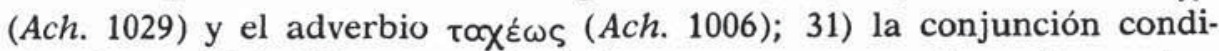
cional ćódv (Ach. 39), que es la única que aparece en las antiguas inscripciones áticas, y la asimismo conjunción condicional 內̄ $\nu$ (Ach. 60), bien atestiguada en jónico; 32) la conjunción $8 \pi \omega \varsigma$ y la partícula \&̌v para introducir las oraciones finales con subjuntivo (Ec. 716) -en total veinticuatro veces en las comedias, aunque ésta es la forma que adoptan las oraciones finales en las inscripciones áticas antiguas-, y la conjunción iv $\alpha(E c .720)$, que introduce oraciones finales con subjuntivo, unas ciento ochenta veces, en las comedias aristofánicas. 33) Encontramos en la lengua de Aristófanes unas veces la partícula postpositiva E $\varepsilon \varepsilon \kappa \alpha(N u$.

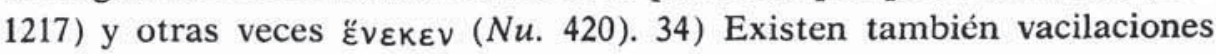

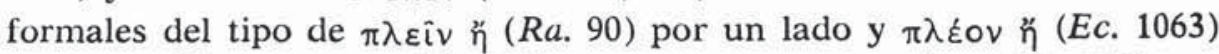

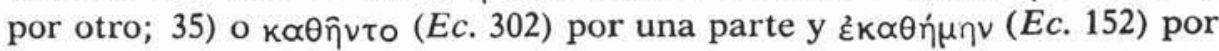

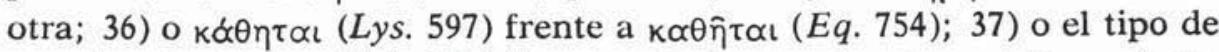
optativo $\dot{\varepsilon} \mu \pi \lambda \eta n \hat{\mu \eta \nu}$ (Ach. 236) frente a la formación, de optativo asimis-

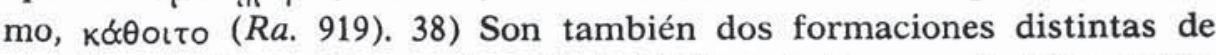

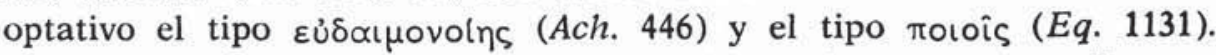
39) En la tercera persona de plural del optativo en voz media, nos

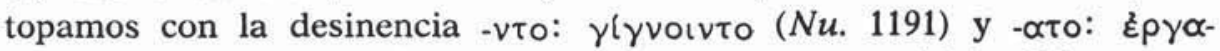
ơlato (Au. 1147). 40) Junto a vocativos: $\bar{\omega} \Lambda \alpha \mu \alpha \chi^{\prime}$ (Ach. 575), encontramos también nominativos empleados en función de vocativo: $\lesssim \Sigma \omega$ кpórņ (Nu. 219). 41) Al lado de la expresión normal en ático para decir "con algo", a saber: $\mu \varepsilon \tau \dot{c}$ con genitivo (Ach. 661), quedan en Aristófanes restos del sintagma oúv más dativo (instrumental) ( $\mathrm{Nu}$. 580). 42) Algunos verbos que se suelen usar constantemente en voz media aparecen a veces empleados en voz activa en la comedia aristofánica; he aquí un ejemplo: $\mu \varepsilon \tau \alpha \pi \varepsilon \dot{\varepsilon} \mu \pi 0$ (fr. 539), pero $\mu \varepsilon \tau \varepsilon \pi \varepsilon \mu \mu \psi \alpha(V .680)$. 43) Frente a formas de voz media que se prestan a servir de voz pasiva, cf. 21: $\delta เ \delta \propto \xi \circ \mu \propto \iota(N u$. 127) "yo seré enseñado», es normal encontrar en la comedia aristofánica las formas pasivas ya bien caracterizadas; por ejemplo: aquellas palabras de un famoso verso de Simónides ${ }^{58}$ : $\varepsilon \pi \varepsilon$ -

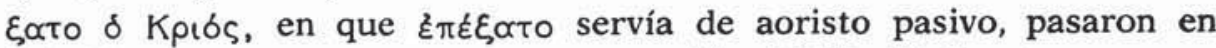

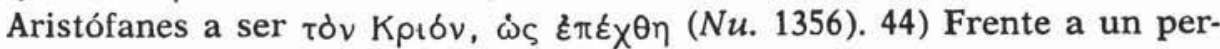
fecto, como $\pi \xi \pi \circ \rho \delta \propto(\operatorname{Pax} 335)$, que todavía conserva su valor resultativo, por lo cual se halla próximo al tema de presente, encontramos

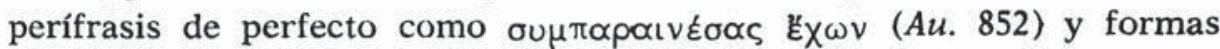

58 Simon. 22 D. $P M G$ 507. Sobre cuestiones de aspecto y voz del verbo griego en época helenística remitimos a B. G. Mandilaras, The verb in the Greek nonliterary papyri, Atenas 1973. 


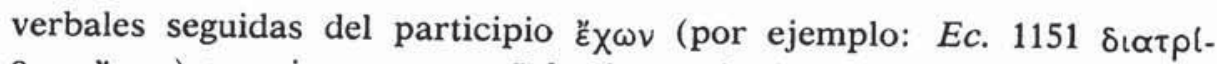
$\beta \varepsilon$ เ $\varepsilon^{\prime} \chi \omega \nu$ ) que sirven para señalar la continuidad ininterrumpida desde el pasado hasta el presente. 45) Frente a una forma de perfecto como $\pi \rho \circ \tau \tau \dot{\tau} \tau \propto \kappa \tau \alpha \iota$ (Lys. 177) descubrimos a veces formaciones perifrásticas, como $\varepsilon \sigma \tau \iota ~ \pi \rho \circ \sigma \tau \varepsilon \tau \alpha \gamma \mu \varepsilon \dot{\varepsilon} \propto(E c .458)$. 46) Aristófanes en un mismo verso de una misma comedia (Ach. 540) emplea el imperfecto antiguo $\chi \rho \hat{\nu} v$

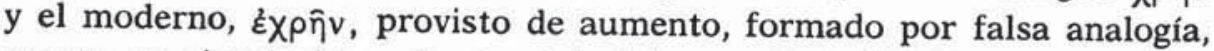
puesto en circulación a finales del siglo v a. J. C. 47) Utiliza asimismo el poeta cómico la preposición els con acusativo para señalar, dejando aparte los usos más corrientes, el fin o el resultado; por ejemplo:

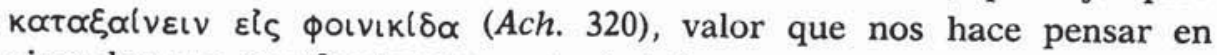

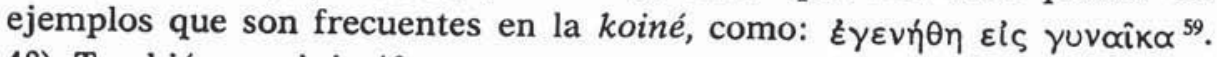
48) También en Aristófanes, como en las inscripciones áticas ${ }^{60}$ del siglo IV a. J. C., el acusativo preposicional ( $\varepsilon$ ls más acusativo) compite con el dativo de destino (datiuus finalis) dependiente de nombres; por

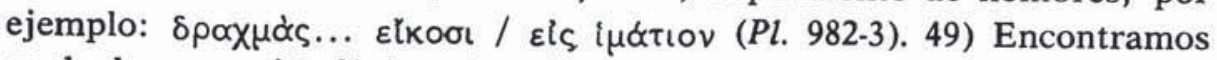
en la lengua aristofánica ejemplos de la conjunción iv $\propto$ empleada en

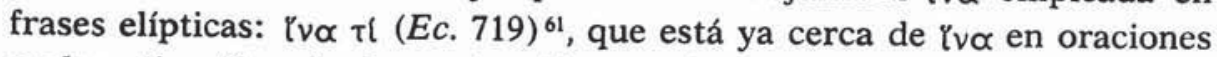
exclamativas $^{62}$ y de la conjunción que introduce frases de órdenes o mandatos ${ }^{63}$, usos de ivœ muy corrientes en koiné. 50) El verbo d́ođó́$\zeta \circ \mu \propto \iota$ significa «saludar» y en este sentido lo emplea Aristófanes; por

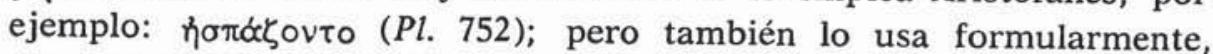

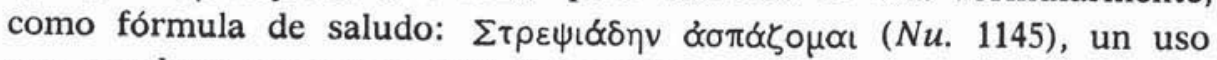
que nos hace pensar en esos imperativos del mismo verbo que en las cartas helenísticas sirven para "mandar saludos». En la Epistola a los romanos de San Pablo leemos un par de saludos expresados con el verbo $\alpha^{\prime} \sigma \pi \nless \zeta \circ \mu \alpha{ }^{64}{ }^{64}$ 51) Hay en la comedia aristofánica muchos giros oracionales que recuerdan la sintaxis de las oraciones del Nuevo Testamento o del griego helenístico en general. Por ejemplo, compárese

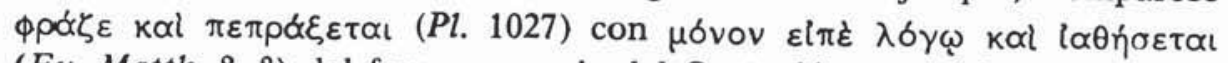
(Eu. Matth. 8, 8) del famoso pasaje del Centurión que pide a Jesucristo la curación de su hijo. 52) Es muy frecuente en Aristófanes que aparezca una frase introducida por ivœ después de un imperativo con el

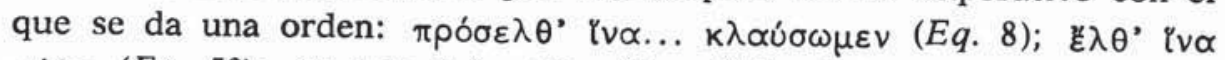

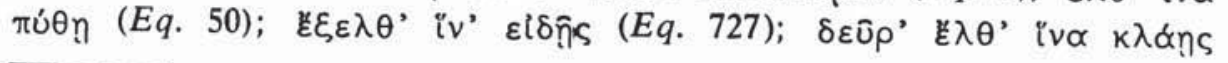

59 LXX Ge. 20, 21.

60 K. Meisterhans-E. Schwyzer, Grammatik der attischen Inschriften, Berlín $1900_{3}$, p. 209.

61 Cf. asimismo Ar. Pax 409; Nu. 1192; Ec. 791.

62 Cf. Arr. Epict. I 29.

63 Cf. Eu. Marc. 5, 23; 2 Ep. Cor. 8, 7; LXX 2 Ma. 1, 9.

(4) Ep. Rom. 16, 22; 16, 23. 


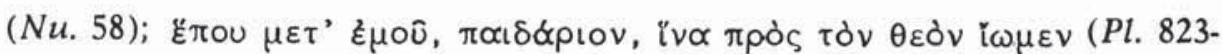
4). Pues bien, en la koiné abundan frases encabezadas por iv $\propto$ porque dependen de un verbo, explícito o sobreentendido, cuyo significado im-

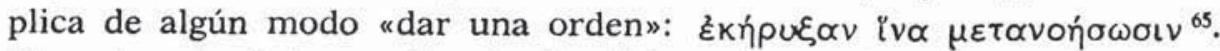

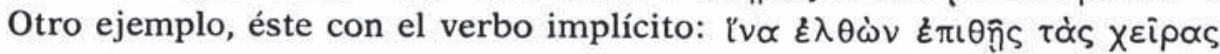
$\alpha u ̛ \hat{n}^{\phi}$. 53) A veces en Aristófanes nos sorprende encontrarnos ante una oración yuxtapuesta a otra, en parataxis, cuando esperaríamos verla como subordinada completiva de ella. Por ejemplo:

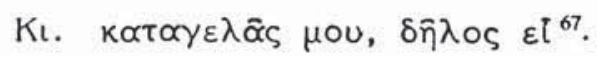

He aquí otro ${ }^{68}$ :

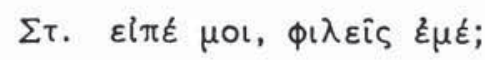

Pues bien, en la koiné y concretamente en el Nuevo Testamento halla-

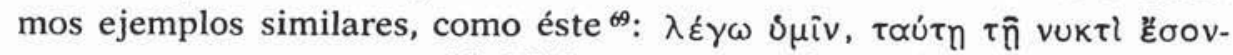

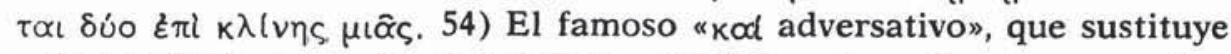
a la partícula $\delta \dot{\varepsilon}$ en la correlación opositiva $\mu \dot{\varepsilon} v \ldots \delta \dot{\varepsilon}$, y que es frecuente en el Nuevo Testamento, lo tenemos ya bien claramente expresado, funcionando como $\delta \hat{\varepsilon}$, en este pasaje ${ }^{x}$ :

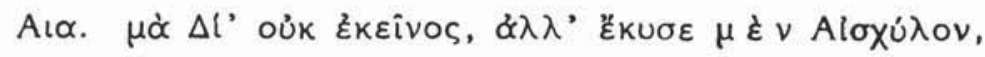

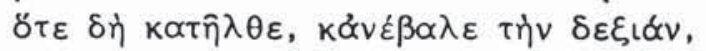

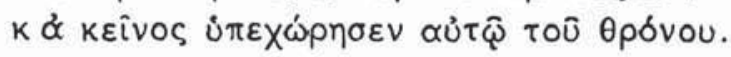

El viejo sistema de las partículas $\mu \varepsilon v^{\prime} \ldots \delta \varepsilon$ se sustituye por otro nuevo. En el Nuevo Testamento, "la parábola del sembrador" la cuenta así

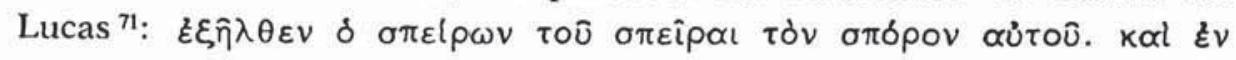

65 Eu. Marc. 6, 12.

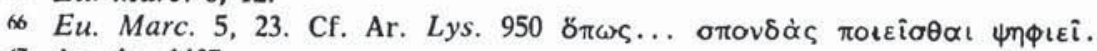

67 Ar. Au. 1407.

68 Ar. $\mathrm{Nu} .82$.

(s) Eu. Marc. 17, 34.

70 Ar. $R a$. 788-790. Cf. Nu. 821; Ra. 1283. Cf. A. Hellwig, «Zur Funktion und Bedeutung der griechischen Partikeln», Gl. 52, 1974, pp. 145-171; W. J. Verdenius, "Note on Hippocrates Airs Waters Places", Mn. 8, 1955, p. 15; «Notes on Menander's Epitrepontes», Mn. 27, 1974, p. 38; «Adversative $\kappa \propto l$ again», Mn. 28, 1975, pp. 189. 190; en contra, J. Blomquist, Das sogenannte $\mathrm{k \alpha l}$ adversativum. Zur Semantik einer griechischen Partikel (Acta Universitatis Upsaliensis), Upsala 1979. Tiene, sin embargo, este autor razón cuando sugiere que la función adversativa de $k \propto$ l resulta de ser el término no marcado respecto de su oposición frente a las adversativas ( $\propto$ Aus der Merkmallosigkeit des $k \propto(\ldots »$, p. 61). Cf. a favor J. A. Hartung, Lehre von den Partikeln der griechischen Sprache, I-II, Erlangen 1832-3, p. 147; J. D. Denniston, The Greek Particles, Oxford $1954_{2}$, p. 292 ss.

71 Eu. Luc. 8, 5 ss. Cf. M. Gonzaga, "Paratactic $k \alpha l$ in the New Testament», CJ $21,1925-6$, p. 583 ss. 


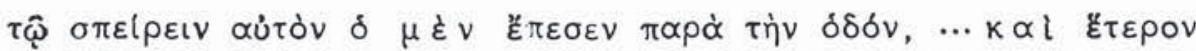

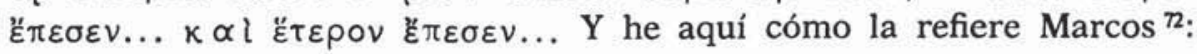

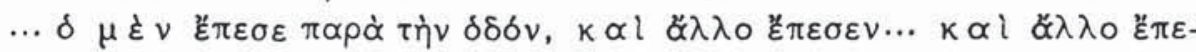

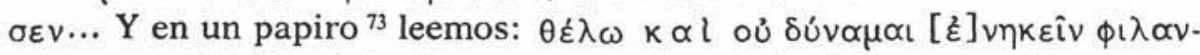
$\theta \rho \omega \pi \varepsilon(\alpha \nu$. 55) En Aristófanes y en griego helenístico encontramos numerosos ejemplos de $k \propto l$ en apódosis o, sencillamente, en frases principales. Es más, Dover ${ }^{74}$ en su edición comentada de Las Nubes (nos referimos a la abreviada) hace notar en el prólogo la gran frecuencia con que aparece en la lengua aristofánica la siguiente estructura sintáctica: "participio... $\kappa \propto$ l y verbo principal». Veamos un ejemplo ${ }^{75}$ :

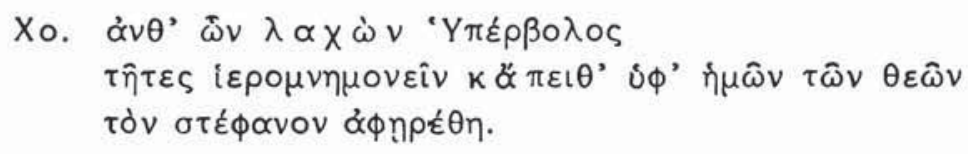

Veamos ahora un ejemplo del griego helenístico de los papiros ${ }^{76}$ :

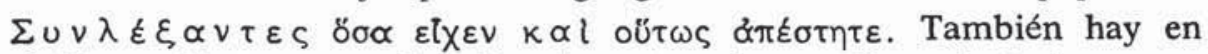
el Nuevo Testamento ejemplos de $\kappa \propto$ en la oración principal; vamos a citar uno en que además de $\kappa \alpha l$ aparece $1 \delta \circ u ́$, lo que nos pone en la pista que nos lleva a relacionar los empleos de la parataxis $k \alpha l$ con el

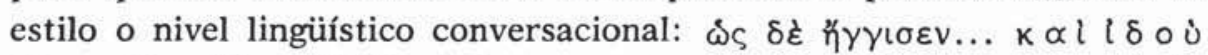
$\varepsilon \xi \varepsilon \kappa о \mu\left(\zeta \varepsilon \tau 0^{\pi}\right.$... 56) Desde luego pertenece al nivel conversacional de una lengua una sintaxis poco complicada, en la que abunda la parataxis, la hipotaxis es más rara y, cuando se emplea, es sencilla. En la sintaxis de una lengua en su nivel coloquial se prefiere, por poner un ejemplo, no salir de la parataxis e indicar las circunstancias temporales de posterioridad mediante los adverbios $\varepsilon i \tau \alpha$, $\ddot{\varepsilon} \pi \varepsilon \iota \tau \alpha$, al hecho de acudir a

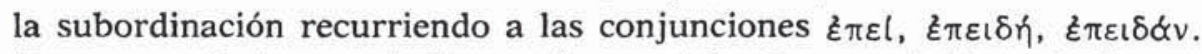
Por eso en la lengua de los papiros y del griego neotestamentario son muy frecuentes estos usos de adverbios $(\varepsilon l \tau \alpha, \varepsilon \varepsilon \pi \varepsilon i \tau \alpha)^{78}$ que constituyen una alternativa de la hipotaxis temporal. Pues bien, he aquí un ejemplo ${ }^{79}$ :

72 Eu. Marc. 4, 4 ss. Cf. F. Blass-A. Debrunner-D. Tabachowitz, Grammatik des neutestamentlichen Griechisch, Göttingen $1965_{12}$, p. 280.

$13 B G U$ IV 1024 (IV-v p.), 5, 14 ss. BGU = Berliner griechische Urkunden (Ägyptische Urkunden aus den Königlichen Museen zu Berlin), Berlín 1895.

74 K. J. Dover, Aristophanes Clouds (abridged edition), Oxford 1970, p. XXXII.

75 Ar. $\mathrm{Nu} .623$.

76 P Grent. II, LXXVII, 11-12. P Grent. II = B. P. Grenfell - A. S. Hunt, New Classical Fragments and other Greek and Latin Papyri, Londres 1897.

$\pi$ Eu. Luc. 7, 12.

78 Eu. Marc. 4, 17; Eu. Luc. 16, 7; Eu. Io. 11, 7.

79 Ar. Ach. $689-690$. 


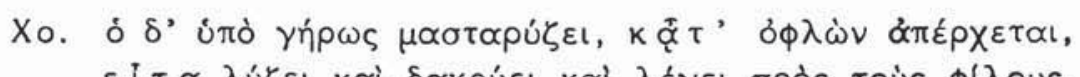

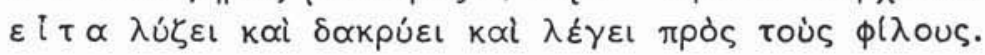

Y como ejemplo de la propensión de Aristófanes hacia esta construcción, y de su fuerte afición a la acumulación verbal y la repetición anafórica para producir comicidad, presentamos la siguiente muestra ${ }^{80}$ :

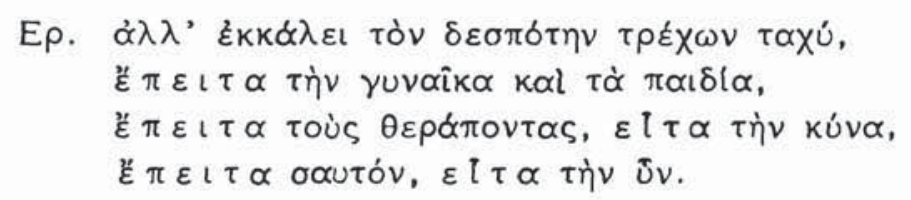

57) Hace ya tiempo que se relacionó la parataxis $\kappa \propto l$ del griego hele-

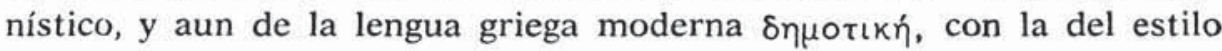
conversacional (lengua hablada) del ático que pudiéramos llamar clásico. Parece ser que las lenguas de todos los tiempos han poseído una forma de expresión, más o menos popular o conversacional, consistente en presentar paratácticamente las frases, unidas por la conjunción equivalente a la del español "y» o la del griego antiguo $\kappa \alpha l$, en vez de emplear para ligarlas conjunciones más específicamente definidas ${ }^{81}$. Esta parataxis $\kappa \propto l$ en parte recibe consagración literaria y en parte no, $\mathrm{y}$, fundamentalmente, caracteriza al estilo oral y popular ${ }^{82}$. Pues bien, he aquí cómo en "estilo $k \alpha$ (" relata el pobre Estrepsíades ${ }^{83}$ los tormentos a que le someten los chinches (o los corintios), todo ello en versos en que se aparean las palabras más desenfadadas y malsonantes con marcadas recurrencias (por ejemplo, la asonancia en -ovoเv):

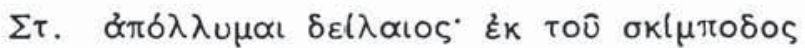

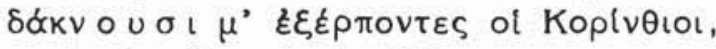

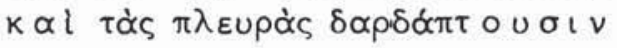

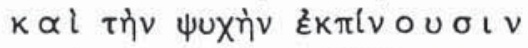

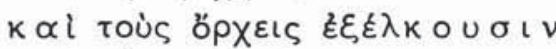

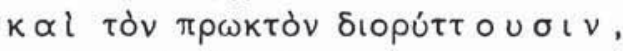
$\kappa \propto i \mu^{\prime} \& \pi \circ \lambda \circ \hat{\sigma} \sigma i v$.

80 Ar. Pl. 1103-6.

81 H. Ljungvik, Bciträge zur Syntax der spätgriechischen Volksprache (Skrifter utgivna av... Kungl. Hum. Vetenskap-Samfundet i Upsala), Upsala 1927, p. 54. Cf. asimismo E. Fränkel, "Zur Parataxe und Hypotaxe im Griechischen, Baltoslawischen und Albanesischen», IF 43, 1926, pp. 290-315.

$82 \mathrm{~S}$. Trenkner, Le style $\mathrm{k} \alpha$ l dans le récit attique oral (Bibliotheca classica Vangorcumiana), Assen 1960, p. 59.

83 Ar. $\mathrm{Nu}$. 709-715. 
Ese "estilo кœ'", propio del cuento o narración oral, lo emplea Aristófanes, incluso en pasajes líricos, cuando expresamente declara que nos va a ofrecer un relato. Veamos, por ejemplo, el «cuento de Melanion" inserto en la Lisistrata ${ }^{84}$ :

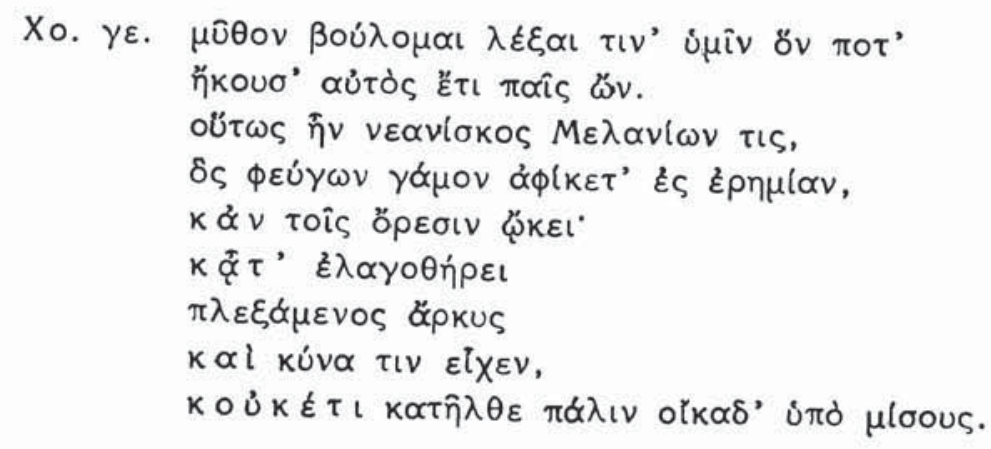

Pues bien, como mostró admirablemente S. Trenkner y ya antes había expuesto $\mathrm{H}$. Ljungvik, estos usos de $k \alpha$ que se atestiguan en la época clásica ${ }^{85}$ son frecuentísimos luego en griego helenístico.

En conclusión: la lengua empleada por Aristófanes en sus comedias como lengua de base del contraste cómico es el ático de finales del siglo v y comienzos del IV a. J. C. Es decir: un ático en el que conviven elementos o rasgos arcaicos y más castizos con otros que proceden del jonio o que se explican por la regularización a que se sometió el ático cuando, bajo la influencia del prestigioso dialecto jónico, dejó de ser la modalidad lingüística usada en el Ática para convertirse en la lengua de un imperio. Esta última modalidad del ático es la que va a ser con el tiempo la koiné.

No es, pues, tan «puro» (si cabe hablar de pureza) el ático de Aristófanes. Un espectador de sus comedias de pronto escuchaba decir छúv al ático modo y luego, sin embargo, oúv, y unas veces oye que el actor buscando unas zapatillas utiliza el plural para referirse a ellas ( $\tau$ ò $\left.\varepsilon \mu \beta \alpha^{\prime} \delta \alpha \varsigma\right)$ y otras veces, aun en la misma comedia, otro actor se refiere a las zapatillas en dual $\left(\varepsilon \mu \beta \alpha \delta \delta^{\prime}[\varepsilon]\right)$ a la manera castiza del ático ${ }^{86} ; y$ tan pronto llega a sus oídos la construcción participial $\gamma \varepsilon \hat{v 0 \alpha \alpha} \lambda \alpha \beta \omega v^{87}$,

84 Ar. Lys. $781-796$

85 K-G II 248. K-G = R. Kühner-B. Gerth, Ausführliche Grammatik der griechischen Sprache, I, II, Hannover y Leipzig $1908_{3}$. Un magnífico trabajo sobre las innovaciones en la sintaxis del griego helenístico es el M. García Teijeiro, «Innova1983, pp. 247-277.

$\approx$ Cf. Ar. Ec. $311 \varepsilon \mu \beta \alpha \delta \alpha \varsigma ; E c .633 \varepsilon \mu \beta \alpha \delta^{\prime}$. Cf. también otros dobletes, como

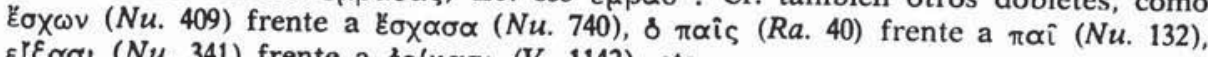
ţळơt $(N u .341)$ frente a $\varepsilon_{0}(\kappa \propto \sigma t(V .1142)$, etc.

87 Ar. Ach. 188. 


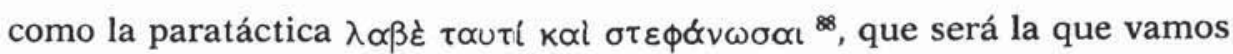
a encontrar en la koiné; por ejemplo: $\varepsilon \lambda \alpha \beta \varepsilon \nu$ oũv toùs «ptous $\delta$

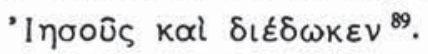

Por otro lado, hemos ido viendo en los puntos tratados en último lugar (a partir del 51) cómo las coincidencias observables entre Aristófanes y la koiné han sido explicadas por Ljungvik y Trenkner en términos de coincidencias del nivel popular, oral o conversacional del ático de Aristófanes y de la koiné. Ahora bien, si el concepto de "ático puro" nos parece desacertado e inexacto, la etiqueta de "popular", "conversacional", etc., aplicada a veces con excesiva generosidad resulta sumamente peligrosa y causante de crasos errores. Hasta ahora ha sido popular y conversacional en griego clásico todo lo que andando el tiempo reaparecía en griego helenístico.

La verdad, empero, es que los dialectos verticales de las lenguas no configuran departamentos estancos, sino que están en contacto permanente y lo conversacional es susceptible de empleo literario, pues hasta en Píndaro ( $P$. IV 87: of $\tau$ i $\pi 00$ ) y en Tucídides (IV 124, 1

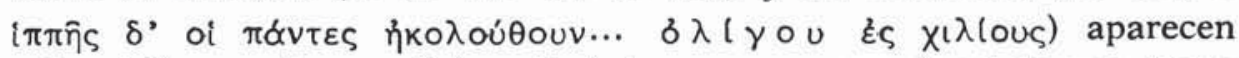
coloquialismos. Rasgos típicos de la lengua conversacional de una época se convierten luego en palabras nada marcadas por su tinte popular o propio de la lengua hablada. Los diminutivos, empleados por Aristófa-

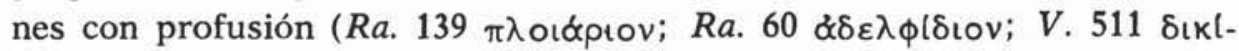

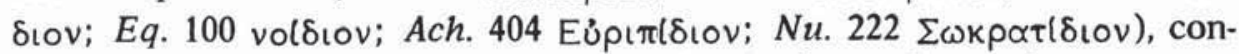
servan todavía en muchos casos el matiz afectivo o despectivo, pero, en suma, un valor expresivo añadido al significado básico de la palabra sobre la que se ha formado. Pero ya el propio Aristófanes no siente como diminutivo la voz $\mu \varepsilon ı$ ṕḱı diminutivo $\mu \varepsilon ı$ เ $\kappa u ́ \lambda \lambda \iota \propto(R a .89)$ para hacer gracia. En los Evangelios, Lucas $\%$, que es el evangelista de mayores pretensiones estilísticas, parece que distingue entre oûs, «la oreja» que cortó San Pedro al sirviente del Sumo Sacerdote en el huerto de Getsemaní, y $\omega \tau$ tov «la orejita” - pequeña diferencia de tono, más afectivo- que le repuso milagrosamente Jesús; pero ni $\mathrm{Mateo}^{91}$, ni $\operatorname{Marcos}^{92}$, ni Juan ${ }^{93}$, que em-

\footnotetext{
88 Ar. Lys, 602.

89 Eu. Io. 6, 11.

90 Eu. Luc. 22, 50 ss. Cf. L. Amudsen, «Some Remarks on Greek Diminutives», SO 40, 1965, pp. 5-16. Para Aristófanes, cf. F. Schmidt, Die Deminutiva auf -tov im Vokativ bei Aristophanes, tes. doct., Zürich, Oberwinterthur 1954.

91 Eu. Matth. 26, 51.

92 Eu. Marc. 14, 17.

93 Eu. Io. 17, 10. Cf. D. Tabachowitz, «Phénomènes linguistiques du vieux grec dans le grec de la basse époque», $M H 3,1946$, pp. 144-179.
} 


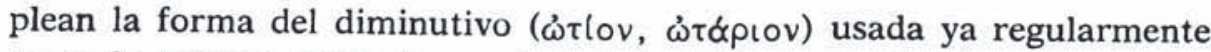
como la palabra normal para la "oreja", sin carga afectiva de ninguna especie, recurren a tal distingo. Así pues, hay que proceder con mucha cautela a la hora de atribuir a un determinado hecho lingüístico el calificativo de "conversacional" o "popular"

El ático que emplea Aristófanes como lengua base en sus comedias es ático que, desde luego, pertenece al nivel conversacional, si por lengua conversacional entendemos aquella variedad situacional de una lengua, provista de un reducido código, en la que se hacen patentes por sí mismas, al lado de la inevitable función referente del lenguaje, la función expresiva, la función conativa y hasta la función fática. Es verdad en parte lo que a propósito del nivel coloquial de la lengua dijera Löfstedt ${ }^{95}$ : que éste y el poético son los estilos más cálidos frente al estilo frío o tono normal de la prosa. Ahora bien, en la poesía el mensaje es más oscuro y menos exacto que en la prosa fría o científica porque en poesía predomina la función poética del lenguaje; en cambio, en el nivel coloquial la función referente del lenguaje no hace falta que se ejerza fuertemente porque otros factores situacionales procuran la comprensión del mensaje. Además el código de la lengua conversacional, como decimos, es reducido, su sintaxis es sencilla, y de este modo son muy notables, por destacar sobre la función referente de la lengua, las demás funciones, como la función expresiva, la función conativa y la función fática. La función primordial de la lengua es la referente, pero suele ésta ir acompañada de otras funciones. En poesía descubrimos una función que tiende al mensaje mismo (función poé-

94 Cf. A. Wifstrand, «Det grekiska prosasprâket. En historik översikt», Eranos 50, 1952, pp. 149-163; cf. p. 163. L. Rydbeck, Fachprosa, vermeintliche Volkssprache und Neues Testament, Upsala 1967, p. 15: «Der Terminus 'Volkssprache' als solcher ist bedenklich und wurde oft missbraucht».

95 E. Löfstedt, Syntaktica II, Lund 1956, p. 365: «Sie sind (sc. die Poesie und die Umgangsprache), kurz ausgedrückt, im Gegensatz zur kühlen, korrekt dahinschreitenden Normalprosa, die beiden wärmeren Stilarten". Sobre lengua griega conversacional cf. C. Amati, "Contributo alle ricerche sull'uso della lingua familiare in Euripide», Stud It 9, 1901, pp. 125-248; F. Pfister, "Vulgärgriechisches in

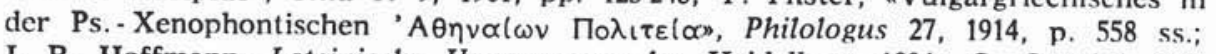
J. B. Hoffmann, Lateinische Umgangssprache, Heidelberg 1936; G. Guarini, "La lingua degli Ichneutae di Sofocle», Aegyptus 6, 1925, pp. 313-329; P. T. Stevens, "Colloquial expressions in Euripides», Hermes 38, Wiesbaden 1976, y anteriormente, "Colloquial expressions in Euripides», ClQ 31, 1937, p. 182 ss.; A. Mancini, "Il dramma satirico grecon, ASNP 11, 1897, pp. 72-79; F. Selvers, De mediae comoediae sermone, tes. doct., Münster 1909; D. Tarrant, "Colloquialisms, semi-proverbs and word-play in Plato», ClQ 40, 1946, pp. 109-117; L. Gautier, La langue de Xénophon, Ginebra 1911; O. Lottich, De sermone vulgari Atticorum maxime ex Aristophanis fabulis cognoscendo, Halle 1881; A. Burckhardt, Spuren der athenischen Volksrede in der alten Komödie, Basilea 1924. 
tica) por lo cual compite con la función lingüística que tiende hacia el contexto (la función referente). Pues bien, en la lengua ordinaria o coloquial hay un hablante, un oyente, un contacto, un contexto y un código. Como el código es reducido, pues el contexto es siempre inmediato (no suele hablarse de cuestiones metafísicas en el nivel conversacional), son muy visibles las funciones no referentes, a saber: la expresiva, en la que se nos revela la actitud o emoción del hablante; la conativa, por la que con diferentes matices se dirige un mensaje al oyente; la metalingüística, por la que el lenguaje se refiere a la propia lengua; y la función fática, cuya primordial función es la de establecer, prolongar o interrumpir el mensaje $\%$.

He aquí algunos ejemplos de esta función que ha sido desatendida a nuestro juicio injustamente: Veamos la repetición de $\alpha \lambda \lambda \alpha \alpha$ a comienzo de frase para señalar que se prolonga una discusión entre Eurípides y Diceópolis ${ }^{97}$ :

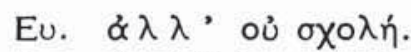

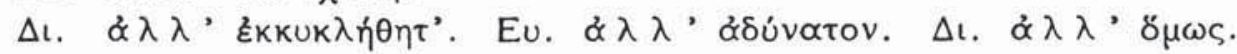

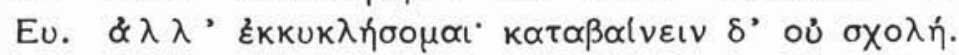

También cabe hablar de función fática cuando nos encontramos ante la interjección $\varepsilon\left[\varepsilon \varepsilon_{\nu}\right.$ empleada para cambiar de conversación o introducir otro tema; por ejemplo ${ }^{98}$ :

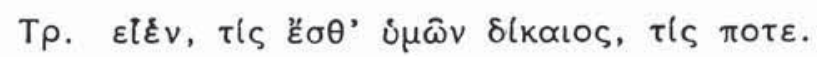

A mitad de camino entre la función fática y la conativa está esa frase hecha del reducido código de la lengua familiar ática de los siglos v-IV

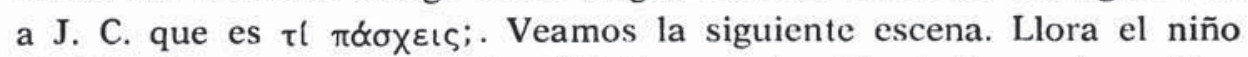
de Cinesias porque su madre, Mirrina, no lo atiende hace cinco días. Cinesias le reprocha a Mirrina tan poco solícita conducta, indigna de una madre ${ }^{99}$ :

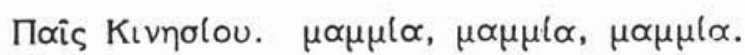

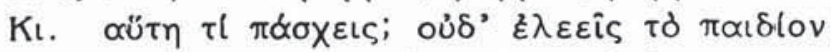

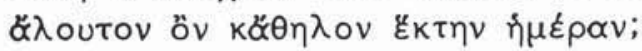

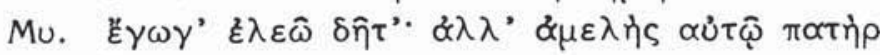

हैoนเข.

96 Sobre estas funciones, cf. R. Jakobson, "La lingüística y la poética», en T. A. Sebeok, Estilo en el lenguaje, trad. esp., Madrid 1974, p. 129 ss.

97 Ar. Ach. 407-409.

98 Ar. Pax 877.

99 Ar. Lys. $879-883$. 


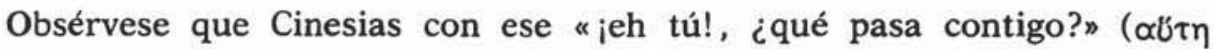
$\tau(\pi \dot{\alpha} \sigma \chi \varepsilon เ \varsigma)$ lo que hace es iniciar una conversación, e introducir la auténtica cuestión, pues la verdadera pregunta es la que sigue: "¿no sientes compasión ( $\varepsilon \lambda \varepsilon \varepsilon \hat{\imath} \varsigma$ ) del niñito?», que es a la única a la que responde Mirrina: «Sí que...».

Para establecer un diálogo bien con otra persona bien con uno mismo (monólogo) sirve el imperativo $\phi \varepsilon ́ p \varepsilon$ convertido ya en partícula de

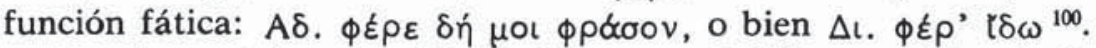

Una forma bien conocida de fomentar el diálogo verificando la comunicación es la consistente en repetir una pregunta pasándola al estilo indirecto: Interlocutor $\mathrm{A}$ : “¿Cómo?». Interlocutor B: «¿Que cómo?». Esto ni significa ni deja de significar nada, sino que es un procedimiento que sirve para conectar el centro emisor con el centro receptor del mensaje. Veamos un ejemplo ${ }^{101}$ :

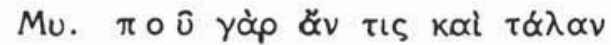

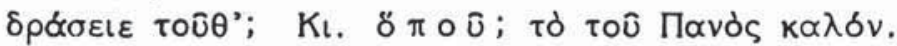

Los ejemplos en que se ve que predomina la función conativa son bastante claros. He aquí uno ${ }^{102}$ :

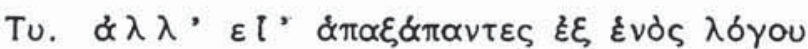

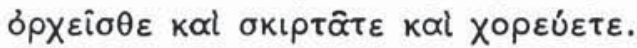

Veamos otro ${ }^{103}$ :

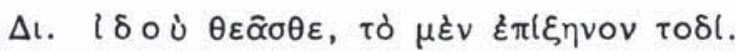

Hay fórmulas enteras, frases hechas, que tienen fundamentalmente esa función, por ejemplo ${ }^{104}$ :

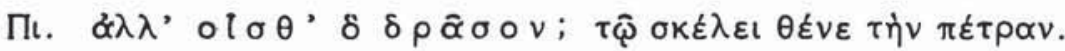

El predominio de la función expresiva es más fácil de detectar en unas ocasiones que en otras. Está clarísima la sorpresa, realzada por la interjección $\mathcal{E}_{\alpha}$, en este verso ${ }^{105}$ :

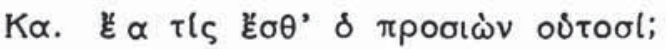

\footnotetext{
100 Ar. Nu. 1088; Ach. 4.

101 Ar. Lys. 910-911.

102 Ar. Pl. 760.

103 Ar. Ach. 366.

104 Ar. Au. 54.

105 Ar. Pl. 824.
} 
Otras veces, en cambio, se percibe menos fácilmente. Estamos pensando en esas alocuciones a espectadores tan sólo simulados, tan estupendamente estudiadas por Fränkel en un conocido artículo ${ }^{106}$. En realidad no son preguntas dirigidas a los espectadores, sino expresiones de los intimos sentimientos del hablante dirigidas no a los espectadores, sino a la generalidad de los hombres, o a un testigo supuesto, es decir: al propio hablante más que a nadie. Exponemos seguidamente un par de ejemplos aristofánicos:

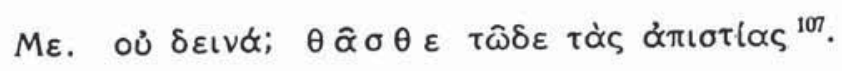

Veamos otro ${ }^{108}$ :

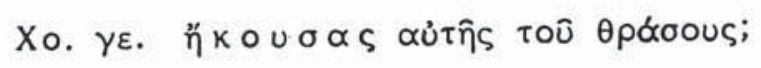

Un nuevo ejemplo de corte idéntico al anterior ${ }^{109}$ :

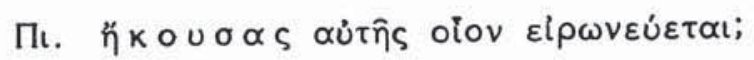

Se trata de falsas alocuciones. El hablante exterioriza sus sentimientos inventándose una segunda persona a la que se dirige. La función metalingüística es asimismo fácil de detectar en este nivel coloquial de la lengua, en el que la función referente actúa en un campo bien reducido y archiconocido por los interlocutores, razón por la cual afloran y se hacen tan conspicuas las demás funciones del lenguaje.

Veamos un caso ${ }^{110}$ :

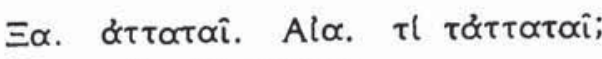

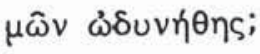

Las partículas tienen que jugar necesariamente un importante papel en la lengua coloquial, ya que no significan, sino que son elementos que facilitan la función expresiva, conativa y fática del lenguaje. Un par de ejemplos:

En la Lisistrata ${ }^{111}$, obsérvese la función del to en estas palabras del pobre Cinesias, tan necesitado de amor:

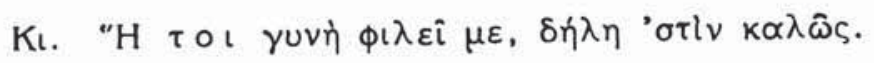

\footnotetext{
106 E. Fränkel, «Anreden an nur gedachte Zuhörer», $M H$ 24, 1967, pp. 190-3.

107 Ar. Ach. 770.

108 Ar. Lys. 379.

109 Ar. $A$ u. 1211

110 Ar. Ra. 649.

11 Ar. Lys. 919. Sobre las partículas, además del libro básico de Denniston, ya citado, cf. J. A. Hartung, Lehre von den Partikeln der griechischen Sprache, I-II,
} 
Estamos a mitad de camino entre la función expresiva y la conativa, pues no sabemos si Cinesias se dirige a un interlocutor (como sería normal con la partícula to ) o habla en soliloquio.

Pocos versos más adelante sugiere Mirrina que para hacer el amor necesitarian una "esterilla" $(\psi(\alpha \theta \circ \varsigma)$, a lo que responde Cinesias corrigiendo el término empleado (función metalingüística: « ¡Qué esterilla!») y añade: "no para mí al menos» "12:

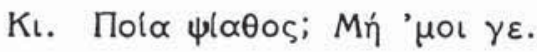

Es evidente que esa partícula $\gamma \varepsilon$ realza el pronombre $\mu \circ$ : función expresiva, similar a la que detectamos en la acumulación de $P l .1001 \mathrm{k} \alpha \grave{l}$ $\pi$ pòs $\varepsilon \pi \imath$ toútoıs. Por otro lado, es bien sabido que en el nivel coloquial abunda ese tipo de partículas cuya función es la de ensartar o enhebrar unas alocuciones con otras o bien introducir nuevas frases para no interrumpir la comunicación, el diálogo (función fática); son esas partículas que se llaman en alemán rein anreihende, anführende Partikeln. Véase, por ejemplo, el contraste entre $\pi \lambda \eta \dot{\nu} v$ ' $\pi \iota \dot{\varepsilon} \zeta \circ \mu \alpha \iota$ ' y $\pi \lambda \eta \dot{\nu} \nu \gamma^{\prime}$ ' $\omega \varsigma \quad \theta \lambda(\beta \circ \mu \alpha l$ ', palabras puestas por Aristófanes en boca de Dioniso nada más comenzar Las Ranas ${ }^{113}$. Jantias acaba de preguntar a su señor, el dios del vino: " $¿$ Digo algo gracioso, de lo que suele hacer

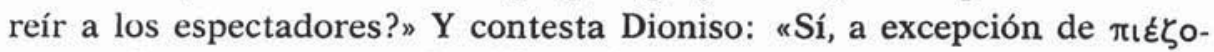
$\mu \alpha \iota, y$ de $\omega \varsigma \theta \lambda(\beta \circ \mu \alpha \iota, » L a$ diferencia entre una y otra expresión reside en el $\omega \varsigma$ recitatiuum, cuya función es la de conectar con el $\varepsilon i \pi \omega$ de Jantias: "¿Digo algo gracioso...?» Estas funciones tan propias de las partículas son, por consiguiente, fáciles de detectar en la lengua conversacional de la comedia aristofánica.

Pero hay todavía otros rasgos que sirven para definir con mayor precisión el nivel conversacional: en él la función referente, por ser reducido el contexto, queda a la zaga de la función expresiva en importancia, intensidad y relieve; piénsese, por ejemplo, en el enigmático e insólito $\tau \dot{\partial} \theta p \varepsilon ́ \tau \tau \varepsilon$ (Eq. 17).

La expresividad tiene primacía sobre la denotación. Veámoslo: La deixis es muy viva ${ }^{114}$ :

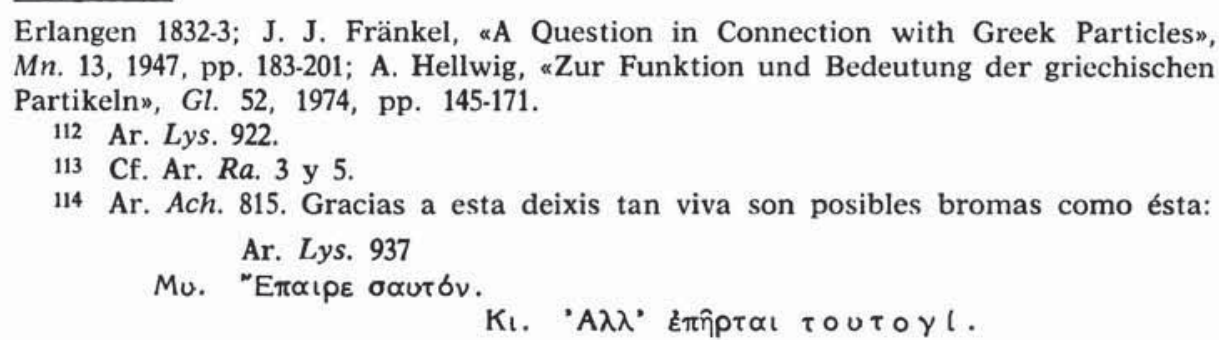




$$
\begin{aligned}
& \Delta \text { เ. } \pi \varepsilon \rho l \mu \varepsilon v^{\prime} \alpha u ̉ \tau o 0 \text {. } \\
& \text { ME. } \tau \alpha \hat{v} \tau \alpha \delta \dot{~} \text {. }
\end{aligned}
$$

El adverbio aủtoû es meramente situacional y la respuesta del megarense es una mera referencia a la orden de Diceópolis, con el valor de asentimiento. El mismo comentario merece la expresión elíptica toû ${ }^{\text {' }}$

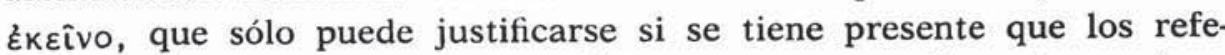
rentes están a la vista y son suficientemente conocidos; he aquí un precioso ejemplo ${ }^{115}$ : Diceópolis se lamenta de que los prítanes lleguen tarde a las asambleas y se empujen unos a otros para ocupar los bancos de la presidencia:

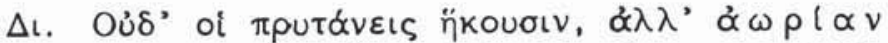

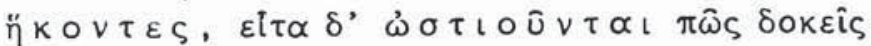

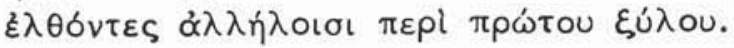

Pues bien, unos versos más adelante se refiere Diceópolis a estas palabras que acaba de pronunciar ${ }^{116}$ :

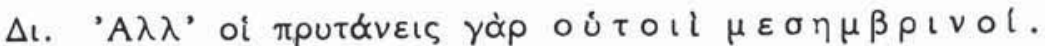

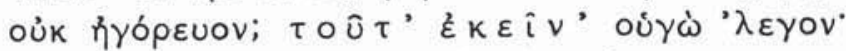

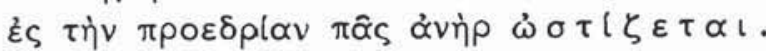

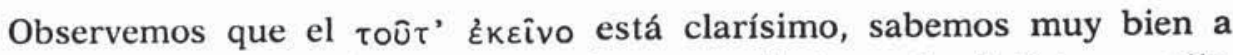
lo que se refiere, así como entendemos perfectamente el ' $\lambda \dot{\varepsilon} \gamma o v$, alle-

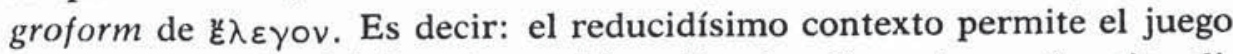
abundante de la deixis y la proliferación de allegroforms (crasis, eli-

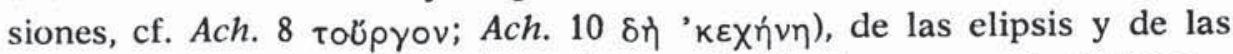
frases hechas, pues sus referencias o significados son -insistimosfácilmente comprensibles o identificables.

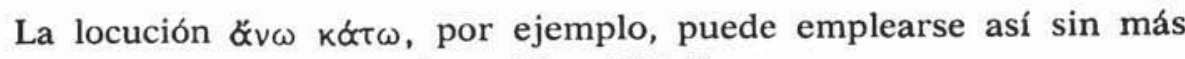
en un par de versos como éstos (Pax 1180-1):

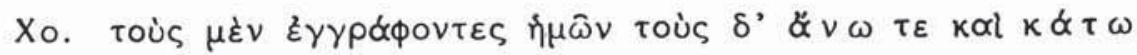

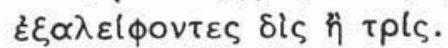

Hay, además, por la misma razón, en la lengua conversacional "palabras - comodín" que se pueden hacer servir para los más diversos usos,

115 Ar. Ach. 23-25.

116 Ar. Ach. 40-42. 


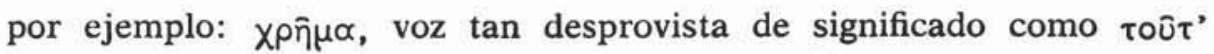
Ékદî̀o. Así leemos este verso en Las Avispas ${ }^{117}$ :

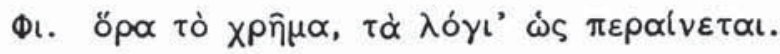

En primer lugar, el imperativo " $\rho \alpha$ no se refiere a una persona concreta o específica (ya hemos tratado de las «alocuciones a oyentes su-

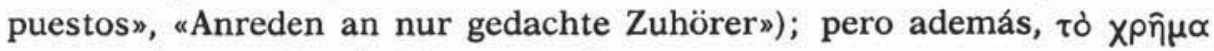

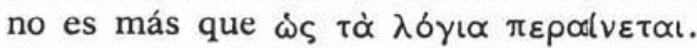

En $\mathrm{La} \mathrm{Paz}{ }^{118}$ un criado, refiriéndose al escarabajo gigante de Trigeo, dice que es un bicho inmundo, maloliente y voraz; y lo dice de este modo:

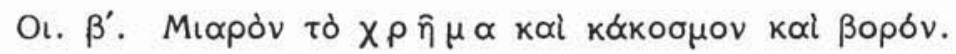

Cómo la función expresiva aventaja a la referente, se percibe en el uso frecuente que se hace de aumentativos y diminutivos. Veamos una locución aumentativa, enfática, provista de un adverbio derivado de adjetivo superlativo, cargada de expresividad ${ }^{119}$ :

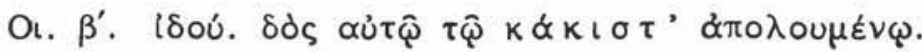

El Criado Segundo de la comedia $L a P a z$ responde con la interjección ¿ઠoú (función conativa) a una orden que le había dado el Criado Primero ${ }^{120}$, y seguidamente se refiere al escarabajo en términos menos descriptivos que emocionales.

La misma función (la expresiva) es bien patente en los diminutivos

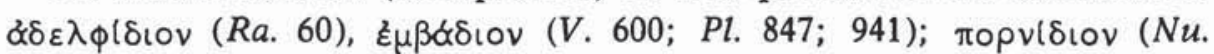

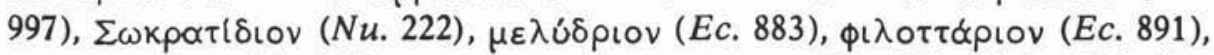

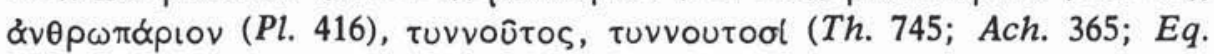
$1220 ; N u$. 392; $R a .139$ ), así como en las siguientes locuciones, aumentativas o diminutivas, pero en todo caso muy expresivas: Cleón es $\delta \varepsilon เ \lambda \partial \varsigma \varsigma \alpha \propto \lambda \alpha \kappa \alpha \tau \alpha \pi u ́ \gamma \omega v^{121}$ y Diceópolis no le da al Labrador ni

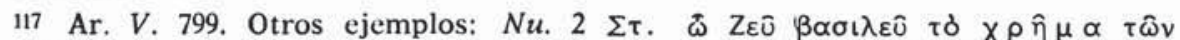

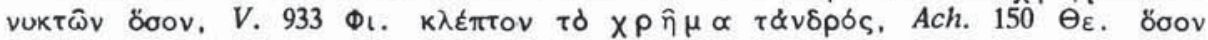

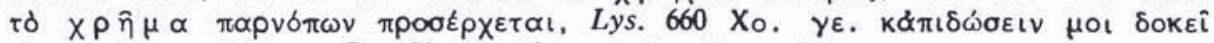

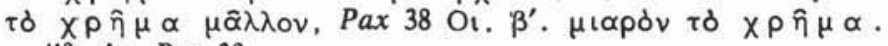

118 Ar. Pax 38.

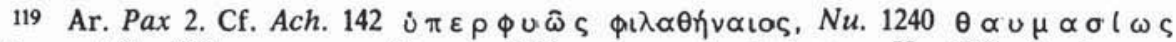

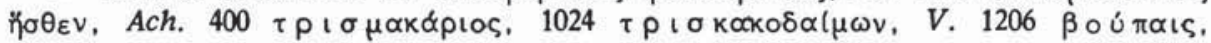
Ec. $730 \kappa \propto \lambda \dot{\eta} \kappa \propto \lambda \hat{\omega} \varsigma$.

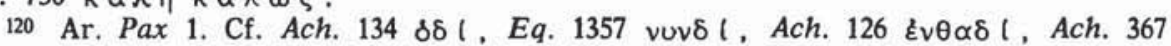
oútool tuvvoutool.

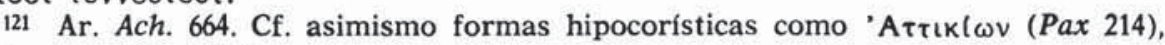
$\mu \alpha \lambda \alpha \kappa l \omega \nu$ (Ec. 1058). 


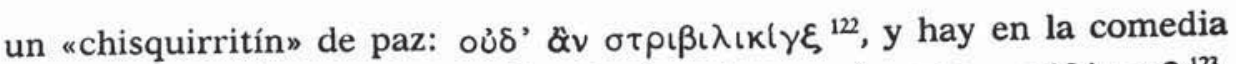

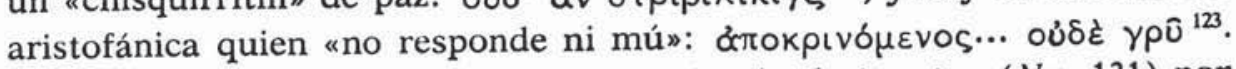

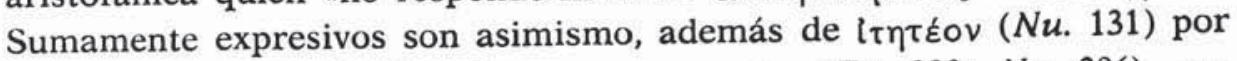

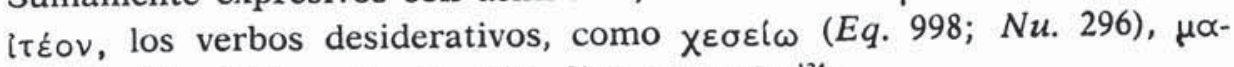

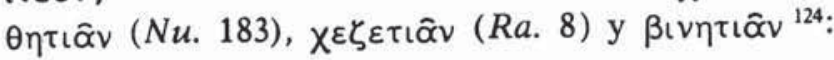

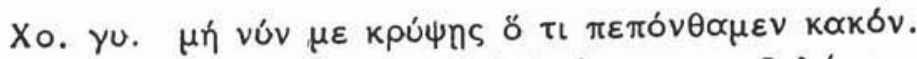

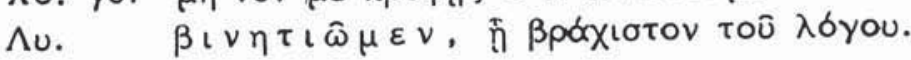

Todo, pues, apunta a que, frente a lo que acontece en otros niveles, en el nivel coloquial la función referente desempeña tan destacado o esencial papel como la expresiva, la conativa y la fática. Determinadas

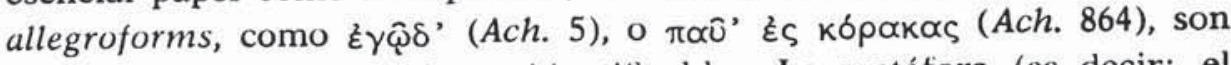
perfectamente reconocibles e identificables. La metáfora (es decir: el desplazamiento de significado de una palabra por neutralización de semas en un contexto ${ }^{125}$, operación que va acompanada, en contrapartida, de una notable ganancia de expresividad por parte de la voz sometida a dicha traslación semántica) tiene en el lenguaje coloquial su connatural asiento. Veamos este ejemplo ${ }^{120}$ :

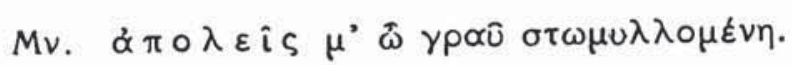

He aquí otro, en el que la voz $\measuredangle \gamma x \delta ́ v \eta$, que literalmente significa «estrangulación», «horca», aparece empleada metafóricamente por Diceópolis con una gran fuerza expresiva ${ }^{127}$ :

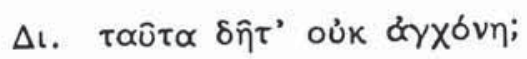

Esas circunstancias especiales del lenguaje coloquial, que vamos verificando, las que permiten y facilitan la metáfora y, en general, propician las voces y los giros fuertemente expresivos, toleran, al mismo tiempo, con gran facilidad las elipsis, los semi-proverbios ${ }^{128}$, los refranes

\footnotetext{
122 Ar. Ach. 1035. Obsérvese el prefijo aumentativo $\lambda \alpha-$. Cf. los aumentativos

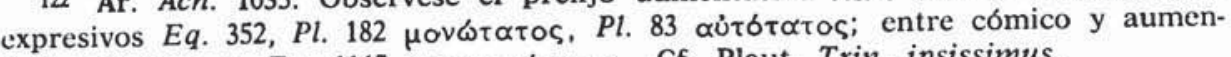

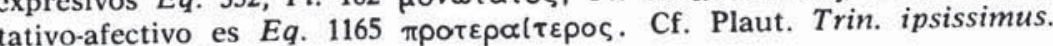

123 Ar. Pl. 17.

124 Cf. Ar. Lys. 714-715.

125 F. Rodríguez Adrados, Lingüistica estructural, I, II, Madrid 1969, pp. 538, 617, 663-4.

126 Ar. Th. 1073.

127 Ar. Ach. 125.

128 Cf. D. Tarrant, «Colloquialisms, semi-proverbs and word-play in Plato», ClO 40,1946, pp. 109-117. Es éste un tema muy interesante que aquí no podemos

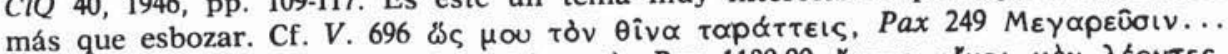
más que esozar.
}

LIV, $2.0-0$ 
simplemente esbozados o enteros, y una sintaxis muy ágil, sencilla y de gran ligereza. Veamos algunos ejemplos:

Basta decir $\kappa \propto \lambda \hat{\omega} \varsigma$ como fórmula de agradecimiento ${ }^{129}$ :

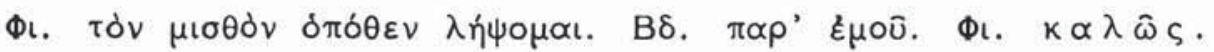

La preposición $\varepsilon^{2} \nu$ o $\varepsilon$ ls seguida de un genitivo (sintagma que se ha originado, según unos, por elipsis de la palabra "casa" o "templo", en dativo o acusativo respectivamente, según otros, en cambio, no es más que un genitivo partitivo de lugar acompañado de preposición) abunda como coloquialismo en la lengua empleada por Aristófanes ${ }^{130}$. He aquí un ejemplo ${ }^{131}$ : se trata de un sabroso diálogo entre el Paflagonio-Cleón y el Salchichero:

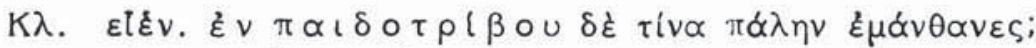

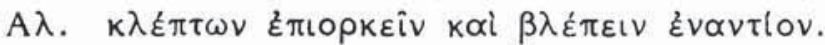

Asimismo, es suficiente la conjunción $\check{\pi \omega \varsigma}$ seguida de un futuro de indicativo para expresar una orden, exhortación, ruego o mandato. El giro es frecuente en Aristófanes ${ }^{132}$. En la comedia Las Nubes lo hemos encontrado cinco veces y abunda en la Lisistrata. Veamos cómo, en esta pieza concretamente ${ }^{133}$, Mirrina exhorta encarecidamente a su marido, con la locución mencionada de ö $\pi \omega \varsigma$ más futuro de indicativo, a votar la paz, a lo que el pobre Cinesias responde con un futuro: «lo pensarés:

$$
\begin{aligned}
& \text { Mu. ' } A \lambda \lambda \text { ' } \ddot{\circ} \pi \omega \varsigma, \bar{\omega} \phi(\lambda \tau \alpha \tau \varepsilon \text {, }
\end{aligned}
$$

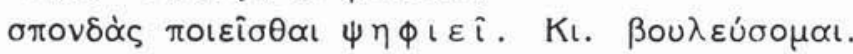

Tres buenos ejemplos de la viveza y agilidad sintáctica de la lengua conversacional aristofánica los constituyen, en primer lugar, la construcción paratáctica de $\beta o u ́ \lambda \varepsilon t$ y el subjuntivo que esperaríamos en hipotaxis; en segundo lugar, el rapidísimo giro del genitivo exclamativo seguido del infinitivo exclamativo articular, y, por último, el llamado imperfecto de momentaneidad para referirse a un suceso tan reciente

\footnotetext{
¿v $\mu \alpha^{\prime} \times n \delta^{\prime} \delta^{\prime} \epsilon^{\prime} \pi \varepsilon \kappa \varepsilon \varsigma$ (el proverbio originario, que se refería a los espartanos,

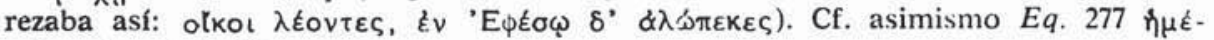

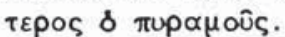

129 Ar. V. 785. Cf. J. H. Quincey, «Greek Expressions of Thanks", JHS 86, 1966, pp. 133-158.

130 Ar. Eq. 1238, Nu. 973, Lys. 407, 1064, 1211, Th. 795, V. 123, 1250, Pl. 621, etc.

131 Ar. Eq. 1238-1239.

132 Ar. Ach. 253, Ec. 82, 297, Lys. 950 e. a., Nu. 257, 489, 824, 1177, 1464.

133 Ar. Lys. 950-951.
} 
que todavía sigue sucediendo, o a un hecho tan general que pertenece al pasado tanto como al presente. Veamos, siguiendo el orden enunciado, una muestra de cada una de las modalidades sintácticas citadas:

En una escena de la Lisistrata ${ }^{134}$, Mirrina ofrece perfume a Cinesias, éste se niega, pero ella insiste:

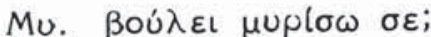

Vamos a ver ahora un ejemplo de genitivo exclamativo seguido de infinitivo, también exclamativo, esta vez no precedido de artículo ${ }^{135}$ :

$$
\begin{aligned}
& \Sigma \tau . \quad \tau \hat{\eta} \varsigma \mu \omega p l \alpha \varsigma \text {, }
\end{aligned}
$$

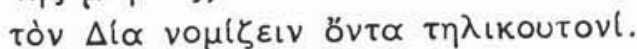

Por último, he aquí un ejemplo del imperfecto de momentaneidad ${ }^{136}$ :

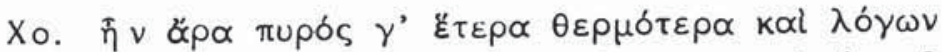

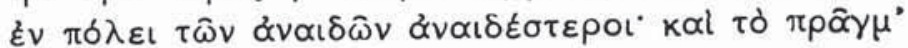

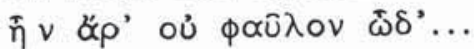

Pasamos ahora a mostrar dos ejemplos que revelan máxima sencillez

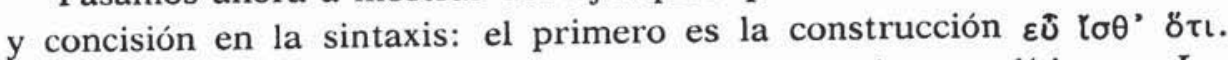
Así responde Euripides a una pregunta de su pariente político en Las Tesmoforiantes ${ }^{137}$. Y con $\sigma \alpha^{\prime} \phi^{\prime}\left\langle\sigma \theta^{\prime}\right.$ ' $\tau \iota$ responde Carión al Sicofanta en el Pluto ${ }^{138}$ :

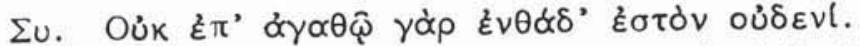

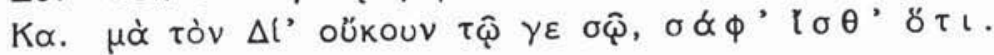

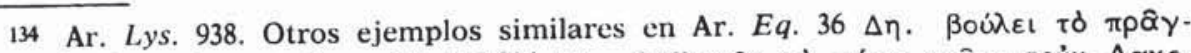

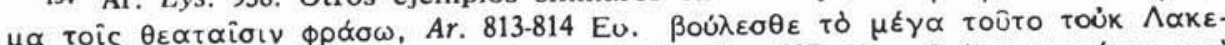

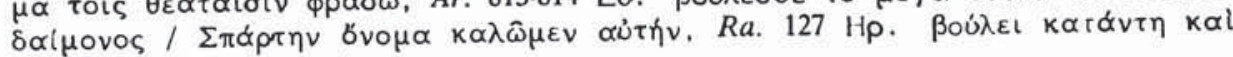
$\tau \alpha \chi \varepsilon \hat{\imath} \alpha v$ бol $\phi p \nless \alpha \sigma \omega$, etc.

135 Ar. $\mathrm{Nu}$. 818-819. Otros ejemplos de genitivo exclamativo: Ar. Ec. $787 \mathrm{Av}$. $\boldsymbol{\beta}^{\prime}$.

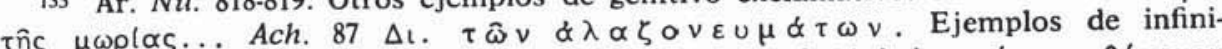

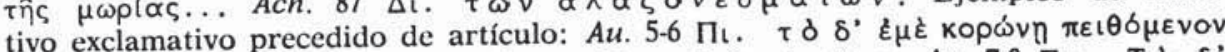
tivo exclamative

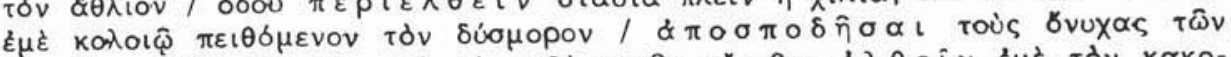

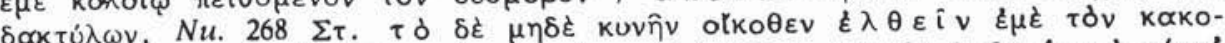

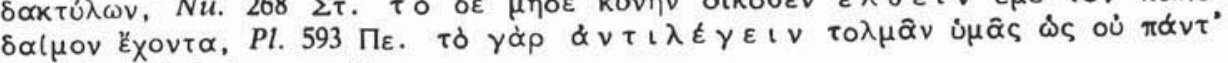

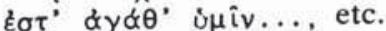

136 Ar. Eq. 384-386. Otros ejemplos: Ar. Eq. $1170 \Delta \eta$. Фs $\mu \varepsilon \gamma \propto v$ \&p $\varepsilon$ I $\chi \varepsilon \subseteq$

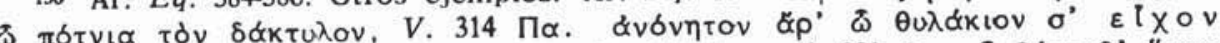

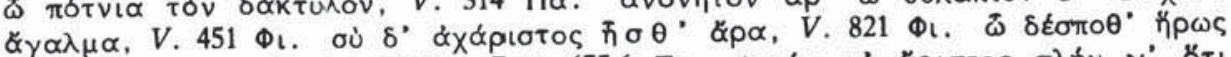

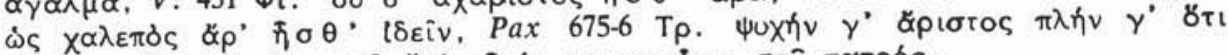

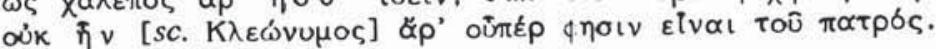

137 Ar. $T h .12$.

138 Ar. Pl. 888-889. 


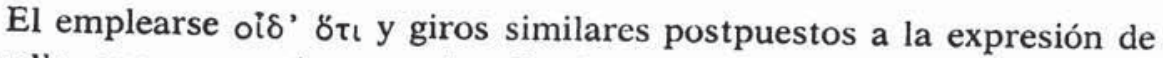
aquello que esperaríamos subordinado y colocado tras la conjunción, significa evidentemente la preferencia por las frases parentéticas, por la parataxis, en suma, respecto de la hipotaxis. En el fondo, como la entonación ayuda en la lengua conversacional a distinguir estas frases parentéticas, se sacrifica la hipotaxis a la parataxis. Veamos unos ejemplos:

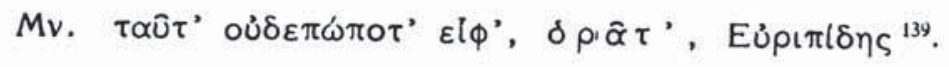

He aquí de nuevo el verbo ópóc usado parentéticamente:

$$
\begin{aligned}
& \text { Mv. } \tau \propto \tilde{u} \theta^{\prime}, \delta \rho \hat{\alpha} \varsigma \text {, } \\
& \text { oủ } \pi \dot{\omega} \pi \circ \tau^{\prime} \varepsilon\left[\pi \varepsilon \nu^{140}\right. \text {. }
\end{aligned}
$$

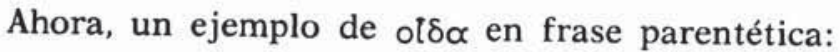

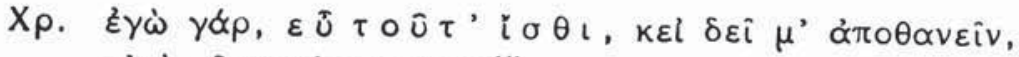

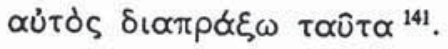

Observemos cómo otras dos fórmulas son empleadas a modo de frases intercaladas en paréntesis:

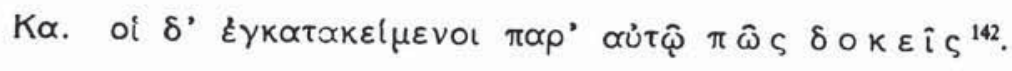

Veamos otra fórmula muy parecida ${ }^{143}$ :

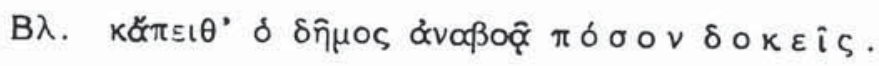

Queda, pues, claro que la sintaxis de la lengua aristofánica, por las razones expuestas, es sencilla, tiende por lo general a la parataxis, y resulta, a su vez, ágil y expresiva. He aquí con qué gracia el Pariente de Eurípides, haciéndose pasar por mujer, cuenta una historia ${ }^{144}$ en la

139 Ar. Th. 490.

140 Ar. $T h .496-497$.

141 Ar. Pl. 216-217.

142 Ar. Pl. 742. Cf. R. Kühner-B. Gerth, o. c. II, p. 354: «Hierher gehört auch die bei den Komikern häufige, aber auch bei Euripides vorkommende Formel $\pi \hat{\omega} \varsigma$ ठokeîs... quid (quantum) censes... supra quam dici potest...»

143 Ar. Ec. 399. Cf. aquellos casos en que se prefiere la locución expresiva inte-

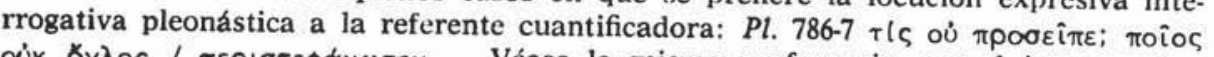

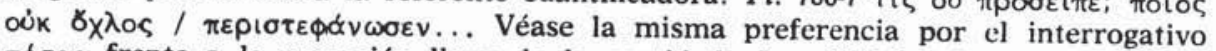

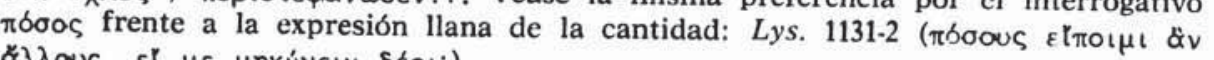

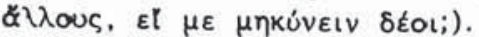

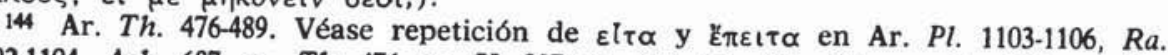
1192-1194, Ach. 687 ss., Th. 476 ss., V. 237 ss., 791 ss., Nu. 494 ss., Ec. 819 ss., Au. 501 ss., 787 ss., 794 ss. Combinación de $\kappa \alpha 1$, kँ $\pi \varepsilon เ \tau \alpha, \delta \varepsilon$, etc. en Ar. Nu. 1373-1376, 
que predomina la parataxis y se recurre espontánea e inesperadamente al estilo directo:

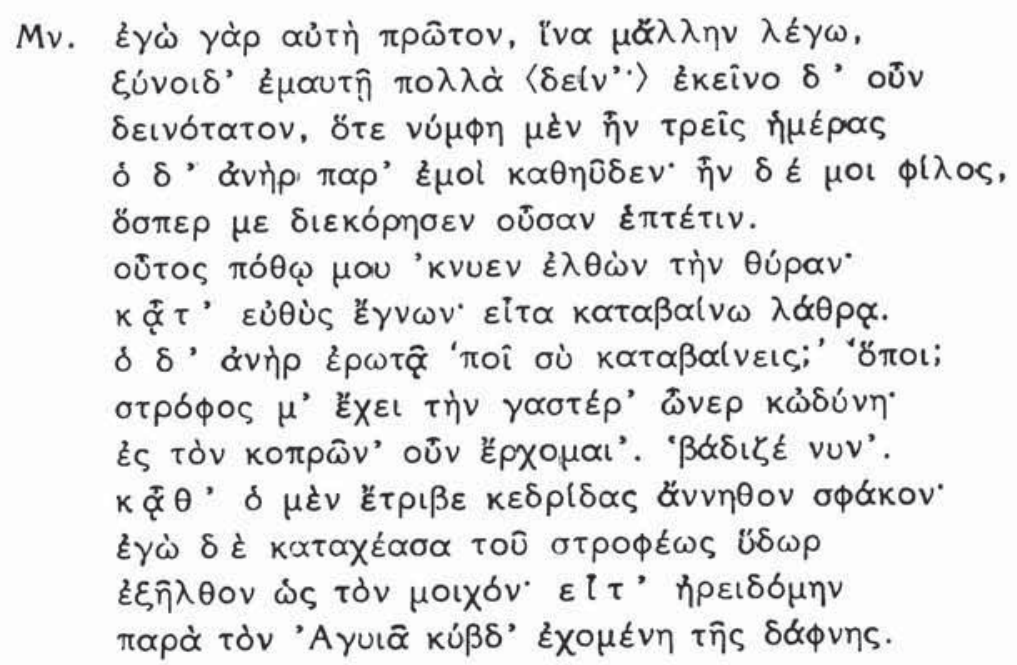

Con la partícula $\delta \varepsilon$, la conjunción copulativa $\kappa \alpha \ell$ y el adverbio $\varepsilon \tau \tau \alpha$ se articula, prácticamente, toda la narración sin más.

Vamos a ver ahora una elementalísima pero ágil y viva sucesión de frases enlazadas por $\kappa \propto l \mathrm{y}$, de pronto $-\mathrm{a}$ modo de frase parentética-, una oración con la partícula $\delta \xi$ que funciona como frase de relativo ${ }^{145}$ :

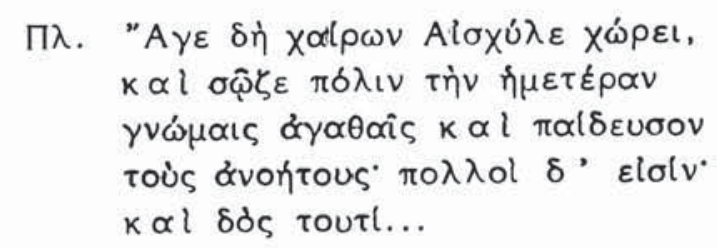

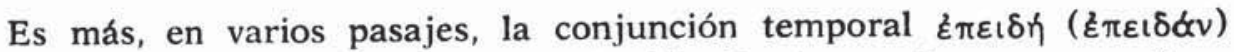
aparece apoyada por un previo adverbio de tiempo $\varepsilon \pi \varepsilon เ \tau \alpha$; por ejemplo ${ }^{146}$ :

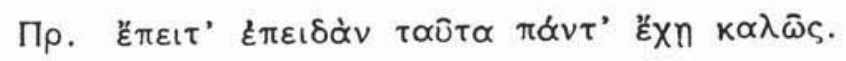

\footnotetext{
Ach. 82 ss., Pax 1168, Ra. 791 ss., Nu. 409 ss., 494-496, etc. Hay dos pasajes antologicos - a nuestro juicio- para mostrar la parataxis con $k \alpha($ unida a adverbios temporales e incluso a conjunciones. Uno es el de la descripción que hace Filocleón de las delicias de ser heliasta ( $V .605$ ss.) y otro es aquel en que un criado de Trigeo, en la comedia $\mathrm{La} \mathrm{Paz}$, refiere cómo actúan las mujeres que tienen amantes (Pax 979 ss.).

145 Ar. $R a .1500$ ss

146 Ar. Ec. 272; cf., asimismo, Pax 619, Pl. 695, Ra. 132, 561, 923.
} 
Los procesos, bien acontecimientos reales, bien operaciones que son tan sólo objeto del deseo y la esperanza, se detallan y especifican en Aristófanes mediante $k \propto l$ y $\varepsilon i \tau \propto\left(\xi^{\prime} \pi \varepsilon(\tau \alpha)\right.$ sencillamente ${ }^{147}$. Y son también muy frecuentes las acumulaciones de hipótesis encadenadas por

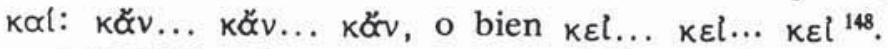

Los relatos de sucesos y las anécdotas más simpáticas de Aristófanes están dispuestos con esta sencilla y a la vez desenvuelta sintaxis ${ }^{149}$.

Pues bien, esa lengua de la comedia aristofánica, el ático de nivel coloquial hablado en los últimos años del siglo $\mathrm{v}$ y los primeros del IV a. J. C., sirve al contraste cómico a fuerza de desentonar con otras modalidades linguísticas, a saber: 1) con el «lenguaje» no articulado de los animales, 2) las lenguas literarias, 3) otros dialectos griegos, 4) el ático hablado por extranjeros, 5) el ático de las capas inferiores de la población, 6) la lengua forjada o inventada por el poeta iocandi causa, con vistas a lo jocoso, festivo o humorístico, 7) las lenguas especiales, 8) la lengua de la élite intelectual, 9) la lengua de las clases nobiliarias, 10) la lengua de la plegaria, 11) las variedades lingüísticas que dependen del sexo de los hablantes, etc.

1. Veamos cómo en estos dos ejemplos que exponemos seguidamente se pasa de lo inarticulado a la frase comprensible:

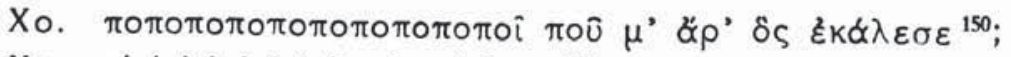

$$
\begin{aligned}
& \text { Xo. } \tau|\tau| \tau|\tau| \tau|\tau i \tau| \tau\left|l^{\circ} \tau\right| v \propto \lambda{ }^{\prime} \gamma o v{ }^{151} \ldots
\end{aligned}
$$

2. Vamos a poner sólo un ejemplo: la parodia del estilo de Eurípides cargado de recurrencias en momentos de especial $\pi \dot{\alpha} \theta$ os. Véase el pasaje lírico de los versos 155 y siguientes de la Hécaba de Eurí-

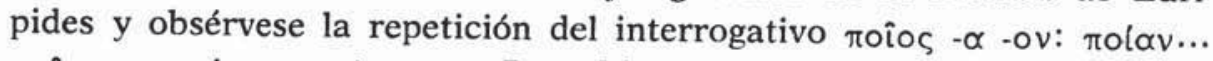
$\pi 0 i ̂ v . . . \pi 0 l \alpha . . . \pi 0 l \alpha$, etc. Pues bien, Aristófanes en la Lisistrata ${ }^{152}$ aparea ese patético estilo con las palabritas que a continuación reproducimos:

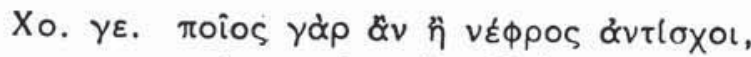

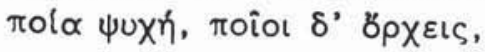

\footnotetext{
147 Cf. Ar. Ra. 923 ss., Lys. 574 ss.

148 Cf. Ar. V. 579 ss., Th. 792 ss., Pax 444 ss.

$149 \mathrm{He}$ aquí una selección de los más chistosos a nuestro juicio: Ar. $\mathrm{Nu}$. 409 ss., 1361 ss., 1375 ss., Au. 494 ss., 501 ss., Ach. 865 ss., Eq. 631 ss., V. 236 ss., 787 ss., etc. 150 Ar. $A u .310-1$

151 Ar. $A u .315$

152 Ar. Lys. 962 ss.
} 


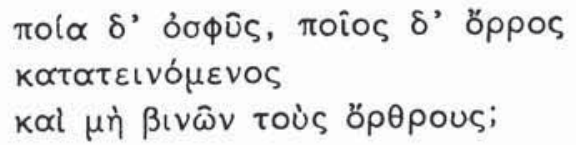

3. El contraste del ático con el laconio, por ejemplo, lo comprobamos en la Lisistrata (1076 ss.), donde leemos estos versos (los dos primeros en laconio de fácil entendimiento, pues la gesticulación y el contexto general de la escena ayudan sobremanera; los dos siguientes, de los que sólo citamos uno, en ático y cargados de doble sentido):

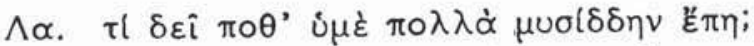

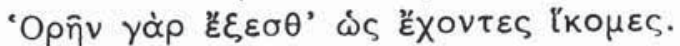

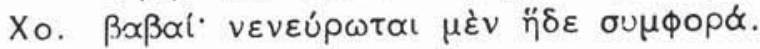

Es laconio el giro preposicional $\pi \circ \theta^{\prime} \dot{\delta} \mu \dot{\varepsilon}$, el verbo $\mu \nu \sigma(\delta \delta \eta \nu$ (cuya $\sigma$ procede de $\theta$, la $\delta \delta$ equivale a ático $\zeta$, y la terminación $-\eta \nu$ de infinitivo temático es comparable a la del ático - $-\varepsilon(v)$; también son rasgos del laconio la contracción de *aēn en ēn: $\delta \rho \hat{\eta} \nu$ y la desinencia de primera persona de plural $-\mu \varepsilon \varsigma$. De todas formas, el Laconio, recitado el primer

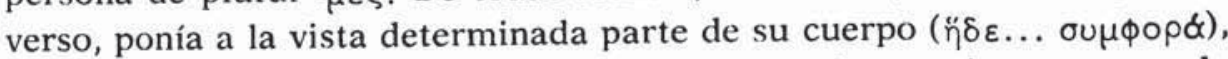
con lo cual el dialecto no constituía inconveniente ninguno para la comprensión de la escena.

4. En Los Acarnienses leemos estos cuatro versos ${ }^{153}$ :

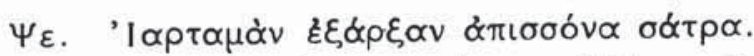

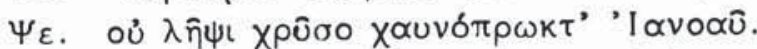

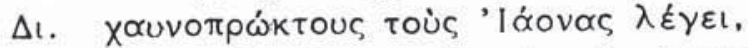

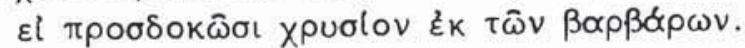

El primero, según los expertos en persa antiguo ${ }^{154}$, es una fórmula de saludo en esta lengua; el segundo es un $\beta \alpha \rho \beta \alpha \rho i \sigma \mu o ́ s$, es griego hablado por un persa que lo pronuncia al modo bárbaro $(\beta \propto \rho \beta \alpha \rho(\zeta \varepsilon l)$, por eso lo entiende muy bien Diceópolis y lo traduce, o, mejor dicho, lo expresa en ático correcto.

5. El Arquero escita de Las Tesmoforiantes convierte regularmente, al hablar, las sordas aspiradas del ático en sordas: Th. 1180 ż $\lambda \propto \pi \rho \delta ́ s$

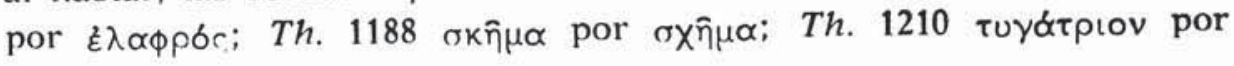

153 Ar. Ach. 100, 104, 106-107.

154 W. Brandenstein - M. Mayrhofer, Handbuch des Altpersischen, Wiesbaden 1964, p. 91; J. Friedrich, "Das Attische im Munde der Ausländer bei Aristophanes», Phil. 75,1918 , p. 274 ss. 
Ouyórprov. Pero, en cambio, en cuanto a la nasal final, $-v$, unas veces

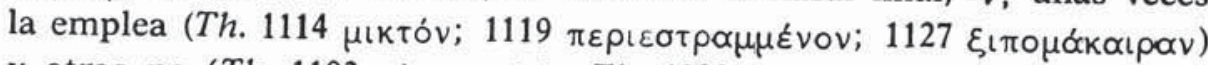

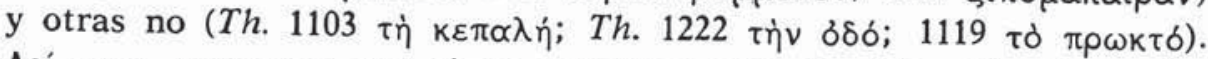
Así pues, pensamos que si en el primer caso la utilización de sordas simples en vez de sordas aspiradas se debe a que en la lengua madre del Arquero, una variedad del iranio, no existen las sordas aspiradas, en el segundo caso, la inconstante ausencia de $-v$ final es una huella del ático vulgar. Existen otras en la jerga del Arquero, por ejemplo:

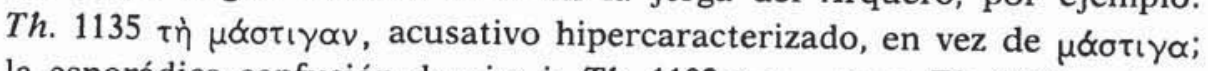
la esporádica confusión de ei e $i$ : Th. $1102 \lambda \varepsilon \dot{\gamma}$ l, pero Th. $1092 \pi \varepsilon u ́ \gamma \varepsilon$, etcétera.

6. De la lengua recreada por el poeta para que al contrastar con el ático conversacional produzca efecto cómico, presentamos este ejemplo de la comedia $\mathrm{La} \mathrm{Paz}^{155}$ :

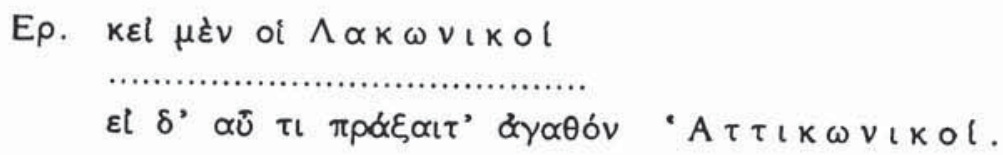

7. Veamos ahora cómo la lengua conversacional contrastando con la lengua de los decretos produce comicidad: 1) Un decreto ateniense

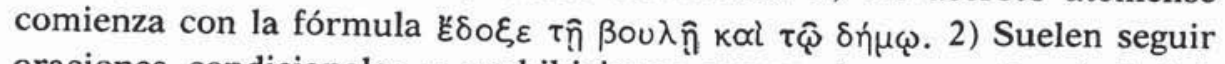
oraciones condicionales y prohibiciones expresadas con $\mu$ ŕ más infini-

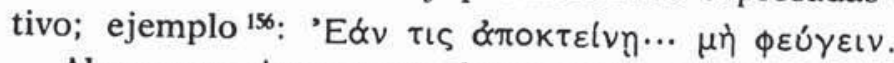

Ahora examinemos un decreto que esgrime una Vieja en Las Asam. bleistas ${ }^{157}$ :

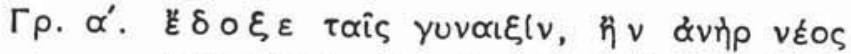

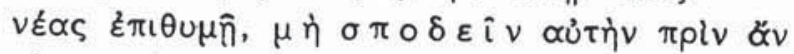

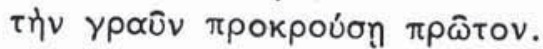

8. Por el léxico en ellos empleado (abundantísimos, excesivos nom-

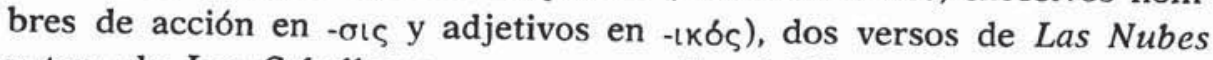
y tres de Los Caballeros parecen parodias del lenguaje empleado por los Sofistas y sus sabios discípulos ${ }^{158}$; he aquí los dos famosos versos de Las Nubes ${ }^{159}$ :

155 Ar. $\operatorname{Pax} 212,215$.

156 Dem. XXIII 53.

15 Ar. Ec. 1015 ss.

158 Cf. E. W. Handley, «-SIS- nouns in Aristophanes», Eranos 51, 1953, pp. 129.

142; C. W. Peppler, AJPh 31, 1910, p. 428

159 Ar. $\mathrm{Nu}$. 317-8. 


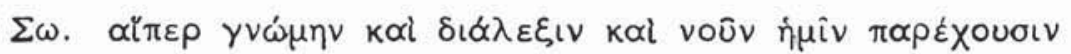

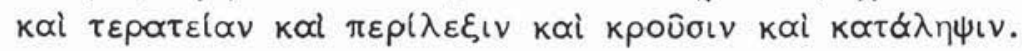

A continuación citamos los tres versos, no menos celebrados, de Los Caballeros ${ }^{160}$ :

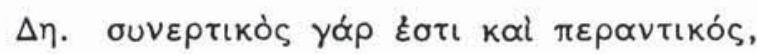

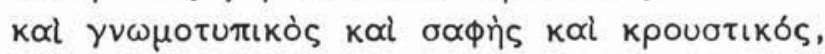

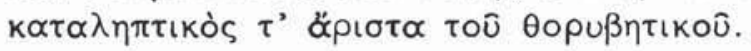

9. Un criado, Demóstenes, exhorta al Salchichero y a los Caballeros con estas palabras tan propias de la noble clase de estos últimos ${ }^{161}$ :

$\Delta \eta$. $\varpi \gamma \varepsilon v v \alpha \delta \propto$ $\alpha \lambda \lambda \alpha \nu \tau 0 \pi \hat{\omega} \lambda \alpha \mu \eta \dot{\eta} \pi \rho \circ \delta \hat{\varphi} \varsigma \tau \dot{\alpha} \pi \rho \alpha \gamma \mu \alpha \tau \alpha$.

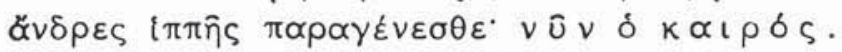

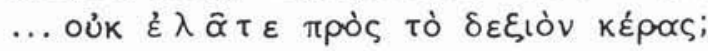

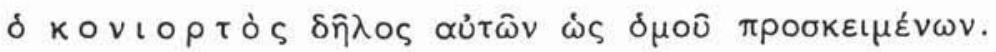

10. La lengua de la plegaria también hace contraste con el ático coloquial en la comedia aristofánica ${ }^{162}$. Veamos una que exhibe un fuerte contraste ${ }^{163}$ :

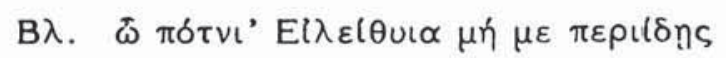 $\delta\llcorner\alpha \rho \rho \alpha \gamma \varepsilon v \tau \alpha \mu \eta \delta \varepsilon \dot{\varepsilon} \beta \varepsilon \beta \alpha \lambda \alpha \nu \omega \mu \varepsilon v 0 v$,

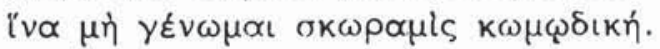

11. Por otra parte, en la comedia de Aristófanes se escuchan frases que sólo pueden proceder de bocas femeninas y contrastan con expresiones masculinas; veamos parte de un altercado entre una mujer de Las Tesmoforiantes, que jura por las diosas, y Mnesíloco, que lo hace por Zeus ${ }^{164}$ :

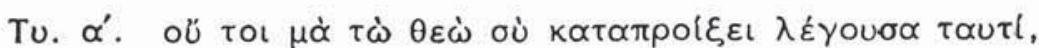

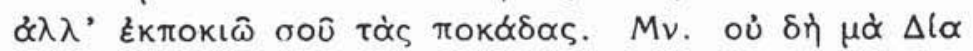

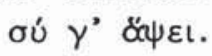

160 Ar. Eq. $1378-80$.

161 Ar. Eq. 240 ss.

162 Cf. H. Kleinknecht, "Zur Parodie des Gottmenschentums bei Aristophanes», Arch. f. Rel. 34, 1936, p. 294 ss., y H. Kleinknecht, Die Gebetsparodie im Altertum, Tüb. Beitr. 28, 1937.

163 Ar. Ec. 369 ss.

164 Ar. Th. $566-7$. 
Todavía podríamos descubrir más contrastes en esa lengua aristofánica tan rica en registros, pero esto desbordaría los límites del presente artículo. En él hemos sido parcos en la presentación de ejemplos y casos concretos, pues nuestra intención ha sido simplemente mostrar cómo se puede ahondar en el estudio de la lengua de base que empleó Aristófanes en sus comedias para lograr el contraste cómico.

\section{A. LÓPEZ EIRE}

